
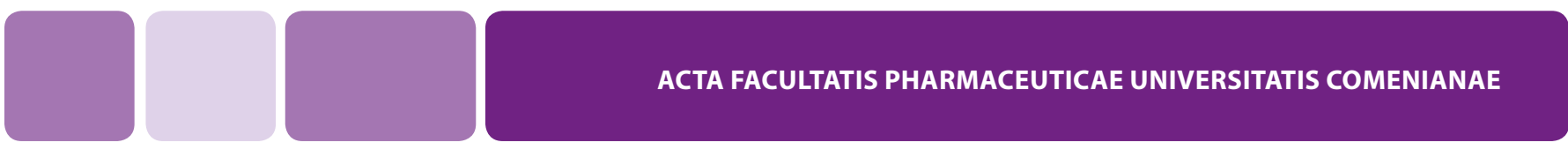

\title{
EFFECT OF GROWING SEASON UPON MICROBIAL STATUS OF PEPPERMINT (MENTHA X PIPERITA L.) RHIZOSPHERE
}

\author{
Adamović D. ${ }^{1}$, Đalović I. ${ }^{1}$, Mrkovački N. ${ }^{1}$, Pandurević T. ${ }^{2}$, Týr Š. ${ }^{3}$, Bjelić D. ${ }^{1}$ \\ ${ }^{1}$ Institute of Field and Vegetable Crops, Maksima Gorkog 30, 21000 Novi Sad, Serbia \\ ${ }^{2}$ University of East Sarajevo, Faculty of Agriculture, Republic of Srpska, B\&H \\ ${ }^{3}$ Slovak University of Agriculture in Nitra, Faculty of Agrobiology and Food Resources, \\ Department of Sustainable Agriculture and Herbology, Slovak Republic
}

\section{Abstract}

Keywords

Acknowledgements

References
Aim In this study, we assessed the number of microorganisms in rhizosphere of peppermint (Mentha x piperita L.) as one of the important aromatic species in Serbia.

Material/Methods The trial was set up on chernozem soil at experimental field of Bački Petrovac, Institute of Field and Vegetable Crops, Novi Sad (northern Serbia) in 2012, 2013 and 2014.

Rhizosphere soil samples were collected from both conventional and organic grown peppermint. Two sampling terms (June and July) were performed in each year of investigation to collect samples for microbiological analyses. Soil samples were analysed by the serial-dilution method followed by plating on different selective mediums. The total number of microorganisms was determined on soil extract agar and number of ammonifiers on MPA medium. The method of fertile drops on Fjodorov medium was used to determine Azotobacter number. The number of fungi was determined on Czapek-Dox medium, and actinomycetes on a synthetic medium. The number of cellulolytic microorganisms was determined on Waksman-Carey medium. Fjodorov medium was used to determine $\mathrm{N}$-fixing microorganisms. The microbiological analyses were done in four replications and the average number of microorganisms was calculated at $1.0 \mathrm{~g}$ absolutely dry soil (Jarak and Đurić, 2004; Gaur and Kaushik, 2012; Adamović et al., 2015). The results were analysed in accordance with three-way model of analysis of variance (ANOVA) using Statistica software (StatSoft Inc. 2013).

Results The obtained results show that a significantly higher number of ammonifiers, azotobacters and free nitrogenfixing bacteria was recorded in 2012 compared to 2013 and 2014. Also, a significantly higher number of azotobacters and free nitrogen-fixing bacteria were obtained with organic than with conventional growing. In addition, significant differences in the numbers of fungi and actinomycetes were recorded between the sampling terms, that is, significantly higher numbers of these groups of microorganisms were found in the second term. The interactions between years, sampling terms and growing variants were observed.

Conclusions It can be concluded from the data presented above that, mostly growing season, then growing system and sampling term in some cases showed significantly higher effects upon microbial status of peppermint rhizosphere.

Mentha x piperita - peppermint - microorganisms - conventional and organic growing - rhizosphere

This study is a part of the TR31073 and TR31013 projects supported by the Ministry of Education, Science and Technological Development of the Republic of Serbia

1. Adamović D, Đalović I, Mrkovački N. Microbial abundance in rhizosphere of medicinal and aromatic plant species in conventional and organic growing systems. Ratarstvo i povrtarstvo 52 2015. (1): 1-6.

2. Gaur S, Kaushik P. Effect of Seasonal Variation on Mycorrhizal Fungi Associated with Medicinal Plants in Central Himalayan Region of India. American Journal of Plant Sciences 2012. (3): 618-626.

3. Jarak M, Đurić S. Mannual of Microbiology. Faculty of Agriculture, Novi Sad, Serbia. 2004. 


\title{
EFFECT OF SEED MATERIAL PREPARATION ON PLANT DENSITY AND FRIUT YIELD OF SILYBUM MARIANUM (L.) GAERTN.
}

\author{
Andrzejewska J. ${ }^{1}$, Ignaczak S. ${ }^{,}$Frias dos Santos P. M. ${ }^{2}$, Martinelli T. ${ }^{3}$ \\ ${ }^{1}$ University of Technology and Life Sciences in Bydgoszcz, Faculty of Agriculture and Biotechnology, \\ Department of Agrotechnology, Poland \\ ${ }^{2}$ Instituto Superior Politécnico de Coimbra, Escola Superior Agrária de Coimbra, Portugal \\ ${ }^{3}$ Council for Agricultural Research and Economics - Research Centre for industrial crops (CRA-CIN), Bologna, Italy
}

\begin{abstract}
Aim Milk thistle [Silybum marianum (L.) Gaertn.] is an important cultivated medicinal plant (Luščáková, Habán a Kobidová, 2015). The fruits - achenes - are extracted for pharmaceutical properties or used as seed for subsequent crops. In temperate climate, milk thistle emergence is uneven, occurring over 1-4 weeks (Andrzejewska and Skinder, 2006), which creates favourable conditions for weed invasion. In view of lack of herbicides, mechanical control is the only current option for weed management. However, it is only effective when cultivated plants emerge fast and uniformly. The aim of this study is to estimate the effect of seed preparation on plant emergence and density, and achene yield of milk thistle.

Material/Methods Field experiments with the cv. Silma were conducted at the Research Station Mochełek (Poland, $53^{\circ} 12^{\prime} \mathrm{N}, 17^{\circ} 51^{\prime} \mathrm{E}$ ) in 2012,2013 and 2015 . Experimental factors were method for seed preparation: (A) thermal - storage at $28^{\circ} \mathrm{C}$ for 3 weeks before sowing (temperature stimulating emergence; Groves and Kaye, 1989), storage at $7^{\circ} \mathrm{C}$ (temperature of soil during sowing), or storage at $18^{\circ} \mathrm{C}$ (temperature of the warehouse); (B) mechanical - segregation of achenes according to TSW (thousend seed weight): large with TSW of $26 \mathrm{~g}$, small with TSW of $22 \mathrm{~g}$, not separated with TSW of $24 \mathrm{~g}$. In 2012 and 2015, sowing was on 10 April and in 2013, on 29 April. Plant density was determined four or five times at weekly intervals. Achene yield was determined after drying at $50^{\circ} \mathrm{C}$.

Results The method for seed preparation had an effect on plant density in 2012 and 2015. In 2013, emergence rate did not depend on the experimental factors, although the highest plant density was obtained then (50 plants $\mathrm{m}^{-2}$ ). Increasing seed storage temperature to $28^{\circ} \mathrm{C}$ resulted in speeding up emergence, particularly in 2012, compared with the seed stored in warehouse conditions. The effect of cooling seed was inconsistent - in the first year, the effect was favourable, and in the last year, negative. When sown early in 2012 and 2015, it was found that the plant density from achenes with TSW of $26 \mathrm{~g}$ was 15\% higher than that from achenes with TSW of $24 \mathrm{~g}$ and $30-40 \%$ higher than from achenes with TSW of $22 \mathrm{~g}$. This relationship remained unchanged from $20^{\text {th }}$ to $48^{\text {th }}$ day after sowing. In 2012 , fruit yield amounted to 1.07 and in 2013, $1.19 \mathrm{tha}^{-1}$ (2015 achenes have not been harvested yet). The method for seed preparation had no effect on the fruit yield.

Conclusion In temperate climate with early sowing times, the use of seed with TSW about $26 \mathrm{~g}$ allows higher initial and final plant density, potentially reducing weed pressure and making their control easier.

Keywords

References

\section{achene, emergence, plant density, milk thistle}

1. Luščáková $D$, Habán $M$, Kobidová R. Production and content of silymarin complex in milk thistle (Silybum marianum L. Gaertn.), Zborník vedeckých prác SSPLV SAV Bratislava, 2015: 63-67. ISBN 978-80-89408-7

2. Andrzejewska J, Skinder Z. Yield and quality of raw material of mik thistle (Silybum marianum L. Gaertn.) grown in monoculture and in crop rotation. Part 1. Reaction of milk thistle to the sowing date. Herba Polonica. 2006; 4: 11-17.

3. Groves RH, Kaye PE. Germination and phenology of seven introduced thistle species in Southern Australia. In Aust. J. Bot. 1989; 37: 351-359.
\end{abstract}




\title{
INFLUENCE OF NITROGEN EXCESS ON PRODUCTION PARAMETERS, METABOLISM AND COMPOSITION OF PHARMACEUTICALLY RELEVANT METABOLITES IN THE MEMBERS OF THE FAMILY LAMIACEAE
}

\author{
Bačkorová M., Eftimová J., Tóth J.
}

University of Veterinary Medicine and Pharmacy in Košice, Department of Pharmacognosy and Botany, Slovakia

\section{Abstract}

Keywords

Acknowledgements

References
Aim Nitrogen $(\mathrm{N})$ has an indispensable function in the plant organism. It has special importance in the creation of amino acids, nucleic acids and other important compounds. Inorganic forms of nitrogen are important signalling molecules $\left(\mathrm{NO}, \mathrm{NO}^{-}\right)$. This work looked at the impact of excess nitrogen on plant metabolism and the production of secondary metabolites in lemon balm (Melissa officinalis).

Material/Methods We used the aerial parts of lemon balm cultivated in hydroponic culture. Nitrogen was applied as $\mathrm{KNO}_{3}$ in two selected concentrations, $50 \mathrm{mM}$ and $100 \mathrm{mM}$. Plants were exposed to weekly action. The role of nitrogen excess, water content, soluble proteins content, assimilation pigment composition, chlorophyll $a$ fluorescence, content of phenols and reactive oxygen species were all selected parameters for assessment of nitrogen tolerance/ toxicity in lemon balm plants. The significance between measured parameters was assessed using analysis of variance. Results We observed an increase in the water content and content of soluble proteins due to nitrogen excess. However, chlorophyll content was only slightly increased. Positive correlation between nitrogen doses and generation of reactive oxygen species was recorded. The content of $\mathrm{H}_{2} \mathrm{O}_{2}$ significantly increased with increased concentration of nitrate. A positive correlation between increased nitrogen doses and the production of phenolic compounds was recorded in this study.

Conclusions From the results of present study, we can assume that the nitrogen applied in hydroponic culture is beneficial for protein production, photosynthetic pigments and production of reactive oxygen species, ROS, (mostly hydrogen peroxide) of lemon balm plants.

Melissa officinalis - nitrogen - nitrate - secondary metabolism

This study was financially supported by University of Veterinary Medicine and Pharmacy in Košice.

1. Sparacino-Watkins C. Stloz JF and Basu P. Nitrate and periplasmic nitrate reductases. Chemical Society Reviews. 2014; 43: 676-706.

2. Sulieman S and Tran P. Symbiotic Nitrogen Fixation in Legume Nodules: Metabolism and Ragulatory Mechanisms. International Journal of Molecular Sciences. 2014; 15: 19389-19393.

3. Ramakrishma A. and Ravishankar, AG. Influence of abiotic stress signals on secondary metabolites in plants. Plant signaling and behavior, 2011; 6: 1720-1731.

4. Arceusz A and Weselovski M. Quality consistency evaluation of Melissa officinalis L. commercial herbs by HPLC fingerprint and quantitation of selected phenolic acids. Journal of Pharmaceutical and Biomedical Analysis. 2013; 83: $215-220$ 


\section{PLANT DEFENCE PROCESSES IN RELATION TO SECONDARY METABOLITES PRODUCTION IN MEDICAL PLANTS}

Abstract

Keywords

References

\begin{abstract}
Aim Plants are sessile organism without possibility to change their environment when their life conditions become unfavourable. Plants are in their natural environment often exposed to negative effect of biotic and abiotic factors. Altered climate conditions, attack of herbivores and pathogens create a complex of stressors that plant organisms have to eliminate in real time. During evolution, various defence processes evolved in higher plants through them they counter and offset a wide range of environmental stresses. Defence mechanisms against abiotic stresses involve production of phytohormone abscisic acid and low-molecular-weight osmolytes, which help cells restore chemical and energetic imbalances induced by the stress and are crucial to acclimation and survival of plants [1]. Plant defence against biotrophic as well as necrotrophic pathogens include various morphological, biochemical and molecular mechanisms that are mediated by different signal pathways. The most important signal molecules are salicylic acid, jasmonic acid and ethylene that trigger and modulate plant resistance through a complex of signal network that even involves participation of other hormones [2].

All mentioned processes result from biotic or abiotic stresses and have an impact on biosynthesis, concentration, transport and storage of primary and secondary metabolites. Secondary metabolites are organic compounds that are not directly involved in the growth, development and reproduction of plants but they are often linked with plant defence. Absence of secondary metabolites results in long-term impairment of the plant's survivability [3]. These compounds usually belong to one of three chemical classes: terpenoids, phenolics and alkaloids. Secondary metabolites, besides participation in defence processes, also represent an important group of phytotherapeutics. In case of limited production of desired metabolites in their natural sources, metabolic engineering may improve their accumulation in plants based on knowledge of the relation between stress and defence plant responses.

Conclusions One of the useful ways of increasing the production of desired secondary metabolite is application of elicitors to plant cell cultures in bioreactor. Plant cell culture technique seems to be one of the possible approaches to obtain valuable plant compounds from their natural sources.
\end{abstract}

Defence processes - Stress - Signal molecules - Secondary metabolites production

1. Fraire-Velázquez S. and Balderas-Hernández VE. Abiotic Stress in Plants and Metabolic Responses. In: Abiotic Stress - Plant Responses and Applications in Agriculture. [ed.] K. Vahdati and Ch. Leslie, InTech, 凶s.I.:: 2013; p. 418, ISBN 978-953-51-1024-8.

2. Yang YX, Ahammed GJ, Wu C, Fan SY, Yhou YH. Crosstalk among Jasmonate, Salicylate and Ethylene Signaling Pathways in Plant Disease and Immune Responses. Curr. Protein. Pept. Sci . March, 30, 2015. (http://www.ncbi.nlm. nih.gov/pubmed/25824390). Accessed: 17. May 2015

3. Bartwal, A., Mall R, Lohani P, Guru SK, Arora S, Role of Secondary Metabolites and Brassinosteroids in Plant Defense Against Environmental Stresses. J. Plant Grow. Reg., 2013; 32 (1): 216-232. 


\title{
ANTIPROLIFERATIVE POTENTIAL OF PHELLODENDRON AMURENSE
}

\author{
Ballová L.' , Kurhajec S. ${ }^{1}$, Petrovová E. ${ }^{2}$, Eftimová J.
}

University of Veterinary Medicine and Pharmacy in Košice, Department of Pharmacognosy and Botany, Slovak Republic ${ }^{2}$ University of Veterinary Medicine and Pharmacy in Košice, Department of Anatomy, Histology and Physiology, Slovak Republic

\section{Abstract}

Keywords

References
Aim Angiogenesis is the process of formation of new blood vessels from a preexisting vasculature. From a pathological point of view, it is necessary for the growth and metastasis of tumours. Tumours cannot grow beyond a few millimetres without blood supplementation. New blood vessels are formed from the host tissue during a process called tumourinduced angiogenesis [1]. Phellodendron amurense Rupr. (PA) is frequently used in traditional Chinese medicine as an anti-inflammatory, adstringent or antidiarrhoeal agent. Berberine is a major active component of the PA bark. Both berberine and the plant exhibit antiproliferative activity by intervening in the different steps of carcinogenesis [2]. Antiangiogenic activity of PA has not been observed till now. Within this study, both antiangiogenic and antioxidant activities of PA bark were pursued.

Material/Methods Antioxidant activity of the ethanolic extract of $P$. amurense bark was measured spectrophotometrically [3]. The influence on the angiogenesis was tested in vivo on chick chorioallantoic membrane (CAM) on embryonic day 10 [4]. CAM was used as a model for the study of the angiogenesis.

Results The extract of PA bark showed the ability to scavenge reactive oxygen species, thus confirming the antioxidant activity. A significant reduction in vessel sprouting and higher percentage of avascular zone was observed after the exposition of CAM to PA bark extract in comparison with non-treated CAM (control).

Conclusions The antioxidant and antiangiogenic activities of PA bark demonstrate its antiproliferative potential. Therefore, it can be applied as a nutraceutical with tumour-modulating properties. These results could contribute to the development of novel drugs for the treatment of cancer or other diseases in which angiogenesis plays a significant role.

angiogenesis - Phellodendron amurense - chorioallantoic membrane - antioxidant - tumour

1. Buhner S. H. Herbal antibiotics: natural alternatives for treating drug-resistant bacteria. Nord Adams: Storey Publishing; 2012. $416 \mathrm{p}$.

2. Hida K. et al., Understanding tumor endothelial cell abnormalities to develop ideal anti-angiogenic therapies. Cancer Sci. 2008; 99: 459-466.

3. Song YS. et al. Inhibition of Angiogenesis by Propolis. Archives of Pharmacal Research. 2002; 25: 500-504.

4. Cacig SI. et al. Spectrophotometric method for the study of the antioxidant activity applied on Ziziphus jujoba and Hydrangea paniculata aqueous extracts. Matica Srpska Proceedings for Natural Sciences. 2006: 87-93. 


\title{
ANTIOXIDANT ACTIVITY AND TOTAL POLYPHENOLS CONTENT OF TWO BASIL (OCIMUM BASILICUM L.) VARIETIES IN DEPENDENCE ON SELENIUM BIOFORTIFICATION
}

\author{
Barátová S. ', Mezeyová, I.' , Hegedűsová, A. ', Andrejiová, A.' \\ ${ }^{1}$ Slovak University of Agriculture in Nitra, Horticulture and Landscape Engineering Faculty \\ Department of Vegetable Production, Slovak Republic
}

Abstract

Keywords

Acknowledgements

References

\begin{abstract}
Aim Spices, at the present, belong to the favourite part of a healthy diet because of their well-known powerfu antioxidant beneficial effects on human health. The aim of this paper is oriented to the impact of selenium biofortification on the content of selected qualitative parameters (total polyphenol content (TPC) and antioxidant activity (AOA) of basil (Ocimum Basilicum L.) depending on the grown variety and term of harvest.

Material/Methods Field experiment was led in a botanical garden SAU Nitra in 2014. There were evaluated 'Dark Green' and 'Red Opal' varieties in three variants; each variant was carried out in quadruplicate. The first variant was untreated (control). In the second variant, selenium as sodium selenate was foliar applied at a concentration of $25 \mathrm{mg} / \mathrm{m}^{2}$, double dose $\left(50 \mathrm{mg} / \mathrm{m}^{2}\right)$ was applied in the third variant. Total polyphenols were determined by the Lachman's method and expressed as $\mathrm{mg}$ of gallic acid equivalent per kilogram fresh matter (Lachman, et al., 2003). Total antioxidant capacity was measured by the Brand-Williams method using a compound DPPH (2.2-diphenyl-1-pikrylhydrazyl) (Brand and Williams et al., 1995).

Results According to the statistical analysis, there was confirmed highly significant impact of variety on both monitored characteristics. 'Red Opal' variety achieved higher average values in the case of TPC (mg/kg of dry matter) as opposed to 'Dark Green' variety, which had higher values in case of AOA (\%). Statistically significant impact of the harvest term was confirmed. For both characteristics - AOA and TPC - the values were higher in the case of second harvest. Application of selenium had statistically significant impact only on the 'Red Opal' variety, on antioxidant activity, in the frame of second harvest, whereas in the control variant, there was reached the average value $92.78 \pm$ $0.37 \%$ and in case of Se Il variant (double selenium application), $93.66 \pm 0.23 \%$.

Conclusions The selenium biofortification as well as variety had significant influence on TPC and AOA according to used statistical analyses, that is why there is strong recommendation of multi-annual results estimation according to submitted methodology.
\end{abstract}

basil - selenium biofortification - polyphenols - antioxidant activity

The work was supported by VEGA project No. 1/0105/14.

1. Brand-Williams W, Cuvelier ME, Berset C. Use of a free radical method to evaluate antioxidant activity. LebensmittelWissenschaft and Technologie. 1995; 28 (1): 25-30.

2. Lachman J, Proněk D, Hejtmánková A, Dudjak J, Pivec V, Faitová K. Total polyphenol and main flavonoid antioxidants in different onion (Allium cepa L.) varieties. Scientia Horticulturae, 2003; 30: 142-147. Available at: http://www. agriculturejournals.cz/publicFiles/51932.pdf. 


\title{
EFFECT OF SUBSTRATES ON LEMON BALM NURSERY PRODUCTION (MELISSA OFFICINALIS L. CV. CITRON)
}

\author{
Beatović D., Kišgeci J., Jelačić S., Lazić A., Nišavić N.
}

Abstract

Keywords

References
Aim Container nursery production with the use of different substrates, has a number of advantages in comparison to classical production and it found its application in the vegetable and fruit growing production a long time ago (Beatović et al. 2010). In Serbia, medicinal, aromatic and seasoning herbs seedlings are still produced in a classical waythe so-called bare root (plants with unprotected root system) in cold and warm seedbeds (Beatović et al. 2012). Garden soil is most frequently used as a substrate, and in this kind of production, plants suffer stress during transplantation and as a result, take longer time for rooting and continuation of growth and development.

Material/Methods In this research, we investigate the influence of nine different substrates in the nursery production of lemon balm variety Citron. The predominant component of the studied substrates was dark peat originating from village Gaj, area South Banat (Serbia). Dark peat was improved by adding white peat, zeolite and different mineral fertilisers.

Results The studies have shown that the best quality lemon balm in the container nursery production are obtained with the use of substrates containing the share of dark peat $(75 \%)+$ white peat $(25 \%)+$ Kristal mineral fertiliser.

Conclusions The obtained study results are significant for the use and promotion of local peat as the main component in the nursery production of medicinal, aromatic and seasoning herbs in Serbia.

lemon balm, container nursery production, substrates

1. Beatović $D$, Jelačić $S$, Moravčević $Đ$, Bjelić $V$, Moravčević $M$, Peat of Gaj as a component of the substrate for medicinal, aromatic and seasoning herbs nursery production. $6^{\text {rd }}$ Conference on Medicinal and Aromatic Plants of Southeast European Countries. 18-22. April 2010. Antalia, Turkey. Book of Abstracts 2010; 6 (22): S103.

2. Beatović $D$, Jelačić $S$, Kišgeci J, Moravčević $Đ$, Krstić- Milošević $D$, Zarić V, Filipović N. Influence of container cell capacity on the properties of lemon balm (Melissa officinalis L.) nursery production. $7^{\text {th }}$ Conference on Medicinal and Aromatic Plants on the Southeast European Countries, $27^{\text {th }}-31^{\text {th }}$ May 2012. Subotica, Serbia. Proceedings 2012; 279-283. 


\title{
ANTIMICROBIAL PROPERTIES OF SELECTED ESSENTIAL OIL COMPONENTS ENCAPSULATED INTO NANOMETRIC SILICA MESOPOROUS SUPPORTS
}

\author{
Bernardos A. ', Janatova A. ', Kloucek P. ${ }^{2}$, Frankova A. ', Smid J. ${ }^{1}$, Kourimska L. ${ }^{2}$ \\ ${ }^{1}$ Czech University of Life Sciences Prague, Department of Crop Production, Prague, Czech Republic \\ ${ }^{2}$ Czech University of Life Sciences Prague, Department of Quality of Agricultural Products, Prague, Czech Republic
}

Abstract

Keywords

References

\begin{abstract}
Aim The use of essential oils ${ }^{1}$ and their bioactive components in agri-food applications suffers from several major drawbacks such as low stability and bioavailability, toxicity for non-target organisms or sensory changes in food applications. Therefore, this study aims at design and evaluation of essential oil components encapsulated in mesoporous silica material ${ }^{2}$ MCM-41 and comparison of their antimicrobial activity with pure non-encapsulated compounds.

Material/Methods The compounds investigated were thymol, thymoquinone, eugenol, carvacrol, diallyl disulfide, allyl isothiocyanate and cinnamaldehyde. We have evaluated their sustained release and antimicrobial activity against selected microorganisms.

Results Among the seven compounds, the greatest antimicrobial action of the encapsulated was observed for cinnamaldehyde, followed by thymol, carvacrol, thymoquinone, eugenol and diallyl disulphide. Compared with the non-encapsulated compounds, the antimicrobial activity was enhanced and prolonged for several days for most of the compounds tested. Evaporation experiments at 25 and $40^{\circ} \mathrm{C}$ revealed that the release per 24 hours varied from 1 to $20 \%$ and 14 to $40 \%$, respectively.

Conclusions The investigation of sustained release of these compounds using MCM-41 revealed that encapsulation of essential oil components into nanometric silica mesoporous supports has great potential in the formulation of natural antimicrobials delivery.
\end{abstract}

essential oils - silica materials - fungi - antimicrobial

1. Kloucek P, Smid J, Flesar J, Havlik J, Titera D, Rada,V, Drabek O, Kokoska L, In vitro inhibitory activity of essential oil vapors against Ascophaera apis. Natural Product Communications. 2012; 7: 253-256.

2. Park SY, Pendleton P. Mesoporous silica SBA-15 for natural antimicrobial delivery. Powder Technology. 2012; 223: 77-82. 


\title{
INFLUENCE OF LOCALITY TO CONTENT OF THE BIOLOGICALLY ACTIVE COMPOUNDS IN THE FLAXSEED
}

\author{
Bjelková M.,' ${ }^{1}$ Hajšlová J.', Schulzová V. ${ }^{2}$, Vrbová M. ', Pavelek M. ', Šmirous P. ${ }^{1}$ \\ ${ }^{1}$ Agritec Plant Research Ltd., Department of Industrial Crops and Legumes: \\ Department Plant Protections 1a, Šmperk, Czech Republic, \\ ${ }^{2}$ University of Chemistry and Technologies, Prague, Czech Republic
}

\section{Abstract}

Keywords

Acknowledgements

References
Aim Flax and linseed (Linum usitatissimum L.), a crop grown worldwide for hundreds of years, is known as a source of fibres for textile applications as well as oils. In addition, flaxseed is used in the food industry in the form of whole seeds and linseed oil as a food supplement. Flaxseed is considered as a functional food because it contains several healthbeneficial substances (Vaisey-Genser \& Morris, 2003). It is known that flaxseed is composed of about $40 \%$ oil, $28 \%$ dietary fibre, $20 \%$ protein, $4 \%$ ash and $6 \%$ moisture (Thompson and Cunnane, 2003). Besides these main nutrients, flaxseed also contains biologically active compounds (secondary metabolites), lignans and carotenoids (lutein) with positive health effects. In flaxseed, which is the richest dietary source of lignans, the most dominant lignan is secoisolariciresinol (SECO). The aim of this study is to evaluate the influence of linseed variety and climatic conditions on the content of SECO, lutein and cyanogenic glycosides in flaxseeds.

Material/Methods Linseed genotypes were grown under the influence of different external factors. The seed products linseed from small-plot field were tested. Statistical evaluations of the recorded data were performed with an analysis of variance and multiple comparisons - Fishers Least Significant Difference, LSD test with statistic programme Statistica.

Results Statistical evaluation within individual years was a difference in the content of SECO, the higher was the samples from the specified region Šumperk (3656 mg. $\mathrm{kg}^{-1}$ ) compared to samples from the specified region Vikýřvice (3222 mg.kg-1). The average content of cyanogenic glycosides was higher in samples from Vikýrovice $\left(2920 \mathrm{mg} \cdot \mathrm{kg}^{-1}\right)$ than Šumperk (2079 mg.kg-1). The results show that in 2009 and 2010, the samples from the locality Šumperk showed significantly higher levels of SECO and lower levels of cyanogenic glycosides compared to Vikýřovice site. There was no statistically significant difference in the content of lutein.

Conclusions These results demonstrated high content of lignans (secoisolariciresinol diglycoside) and low content of carotenoid lutein in flaxseed.

Linum usitatissimum L. - linseed - lignans - secosoisariciresinol - phytoestrogens - lignans - lutein secoisolariciresinol - cyanogenic glycosides - seed

This study was carried out within the projects NPVII 2B06087, LH12226, supported by the Ministry of Education, Youth and Sports of the Czech Republic.

1. Thompson LU and Cunnane SC. Flaxseed in human nutrition, 2nd ed. Illinois: AOCS Publishing,. 2003. ISBN 1-893997$38-3,458 \mathrm{p}$

2. Vaisey-Genser MA and Morris DH. Introduction History of the cultivation and uses of flaxseed, In Muir AD. and Westcott ND. Flax: the genus Linum. London: Taylor \& Francis. 2003. ISBN 0-415-30807-0, p. 299. 


\title{
THE ENZYME-RESPONSIVE CONTROLLED RELEASE OF EUGENOL FROM BIOINSPIRED MESOPOROUS SILICA NANOPARTICLES AND THEIR USE AGAINST ASPERGILLUS NIGER
}

\author{
Božik, M. ', Bernardos A. ${ }^{1}$, , Montero A. ', Martínez-Máñez R. ${ }^{2}$, Klouček P. ${ }^{1}$ \\ ${ }^{1}$ Czech University of Life Sciences, Faculty of Agrobiology, Food and Natural Resources, \\ Department of Quality of Agricultural Products, Praque, Czech Republic. \\ ${ }^{2}$ Centro de Reconocimiento Molecular y Desarrollo Tecnológico (IDM), \\ Universitat Politècnica de València, Camino de Vera s/n, E-46022 Valencia, Spain.
}

\section{Abstract}

Keywords

References
Aim The essential oils and their components are known for their antimicrobial and antifungal activity. But, the use of essential oils components (EOC) as anti-fungal agents suffers from several major drawbacks, such as low stability and bioavailability, toxicity for non-target organisms or sensory changes in food applications. These compounds are very volatile, they often evaporate before they exhibit antifungal activity; for that reason, it is very interesting to release them in a sustained manner to reduce their volatility and prolong their biological effect.

The aim of this study is the use of new biocompatible system for the controlled release of EOC and comparison of its antifungal activity with pure compound.

Material/Methods The system is based on the employment of bioactive plant-derived substance, eugenol encapsulated in silica mesoporous nanoparticles (SMPs) and the surface modified by the grafting of maltodextrin molecular gates. In the presence of the stimuli (such as exogenous enzymes from the fungi with amylolytic activity), the gate is 'opened' and allows the EOC release.

This work evaluates sustained release of eugenol and the in vitro inhibitory activity of eugenol in the vapour phase against Aspergillus niger encapsulated in SMPs and compared with the pure component.

Results It was found that the eugenol encapsulated in the silica mesoporous nanomaterial MCM-41 display remarkable enhanced antifungal properties when compared with the pure eugenol. It has been demonstrated that the attachment of a maltodextrin derivative on the surface of SMPs supports provides a suitable method for the design of mesoporous systems that are able to deliver EOC by a biocontrolled uncapping using exogenous enzymes from the A. niger, hence improving their antifungal activities.

Conclusions This new biocompatible system for the controlled release of EOC is a new method to prolong the antifungal effect of EOC. The combination of active substance and different gates could find application in other fields of study in medicine or agricultural sciences.

biocompatible - controlled release - volatility - essential oils

1. Bernardos A et al. Antifungal effect of essential oil components against Aspergillus niger when loaded into silica mesoporous supports. J. Sci. Food Agric. 2014; Available at http://onlinelibrary.wiley.com/doi/10.1002/jsfa.7022/ epdf

2. Janatova $A$ et al. Long-term antifungal activity of volatile essential oil components released from mesoporous silica materials. Ind. Crops Prod. 2015; 67: 216-220. 


\section{MORPHOLOGICAL EVALUATION OF THE GENETIC RESOURCES OF SALVIA SPECIES}

\section{Čičovál.}

Abstract

Keywords

Acknowledgements

References
Aim The aim of this study is the evaluation and comparison of 12 genetic resources of the Salvia genus. The investigated plants originated from different areas of Slovakia and the Czech Republic. The plants were cultivated in the Gene Bank of the Research Institute of Plant Production in Pieštany.

Material/Methods The plant nursery of basic evaluation of genetic resources of the Salvia genus was established in 2014. The international descriptor (Descriptor List Salvia officinalis L., 2011) was used for the assessment during the whole vegetation period. Morphological evaluation: plant growth habit, plant height, variability of populations, plant diameter, stem hairs, stem hairs type, number of internodes, colour of fully grown leaf, length and width of the leaf, blade shape, shape of the leaf margin, length and width of inflorescence, colour of corolla, fresh biomass, dry biomass, time of early flowering, time of full flowering. All evaluated genetic resources are perennial herbs with leaves distributed all around the stems, leaves with a dentate and entire margin. A great diversity is demonstrated in the length of plants, length of inflorescence, shape and density of leaves, yield of fresh and dry biomass.

Results The highest genetic resources were R 9/02 (S. aethiopis) 1118 mm, SVKPOVIN2011-3 (S. pratensis) 983 mm belonged to the highest varieties. The total plant height was in 2014 on average $728 \mathrm{~mm}$. The longest leaves with genetic resources 59/94, SVKBUR08-6, R 9/02 all come from the area of Slovakia. Genetic resources with the shortest leaves came from the highlands CZEVRCH08-81 (S. verticillata). Some genotypes were characterised by high density leaves, for example, Krajova. We monitored the stem hairs type and stem hairs density that showed very variable, such as the genotypes R9/02 (S. aethiopis) and 59/94 (S. sclarea) had hair on the stems, flowers and leaves, but for the genotype SVKPOVIN2011-3, the hair was manifested only on the stem. The length and width of the leaf was measured at the middle of the plant. The length was measured at intervals of $61.8-150.8 \mathrm{~mm}$ and the width of leaves ranged from 22.8 to $91.4 \mathrm{~mm}$ in the year 2015 .

Salvia - morphological trait - evaluation - genetic resources

This work originated thanks to the support within Operational Programme Research and Development for the project: 'Transfer, use and dissemination of research results of plant genetic resources for food and agriculture' (ITMS: 26220220058).

1. Kahramani A. Celep F, Dogan M. Comparative, morphology, anatomy and palynology of two Salvia L. species (Lamiaceae) and their taxonomic implications, Bangladesh J. Plant Taxon. 2009; 16(1): 73-82.

2. Mossi AJ. et al. Morphological characterisation and agronomical parameters of different species of Salvia sp. (Lamiaceae), Braz. J. Biol. 2011; 71(1): 121-129. 


\title{
POSTHARVEST LOSSES OF ESSENTIAL OIL OF LAVENDER FLOWERS
}

\begin{abstract}
and a lot of them were already seriously published in literature. However, only a few Arabhosseini et al.; Usai et al. studied the course of the EO losses during the storage of the dry plant material before EO yield analysis. The aim of this study is to analyse the EO content changes of two Czech Lavandula angustifolia Mill. varieties, 'Krajová' and 'Beta', in the period between the harvesting and chemical analysis.

Material/Methods Full blooming inflorescences of at least 120 plants of each cultivar were dried in a field drying chamber. The storage took place in paper bags in a dark room at room temperature. The first samples of lavender flowers, which were removed from the stems before the hydrodistillation, were analysed between 43 (in 2011) and 66 (in 2009) days after harvesting and then almost every week until the plant material ran out. The last samples were taken between 158 (in 2012) and 310 (in 2008) days after harvesting. Dry flowers $(20 \mathrm{~g}$ ) were submitted to hydrodistillation with a Clevenger-type apparatus. The EO was co-distilled with $500 \mathrm{ml}$ of distilled water for $4 \mathrm{~h}$. The mean values of two extraction yields are reported.

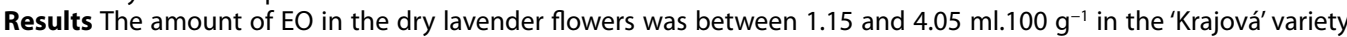
and $3.80-8.95 \mathrm{ml}^{1} 100 \mathrm{~g} \mathrm{~g}^{-1}$ in the 'Beta' variety. Among the treatments, the continual loss of oil was obtained for both the varieties and all the years that were treated. A linear regression showed the average EO yield loss of $0.007 \%$ per day, which means about $2.56 \%$ per year.

Conclusions An 8-year experiment proved that during the long-term storage of dried lavender flowers, a gradual reduction in the total content of EO occurs at a rate of about $0.007 \%$ per day, which means about $2.56 \%$ per year.
\end{abstract}

Abstract

Aim The amount of the essential oil (EO) produced from lavender and other aromatic plants depend on many factors

Keywords

Acknowledgements

References
Lavandula angustifolia L. - storage - essential oil content

Financial support of the National Programme on Conservation and Utilization of Plant, Animal and Microbial Genetic Resources for Food and Agriculture No. 206553/2011-MZE-17253 is gratefully acknowledged.

1. Arabhosseini A, Huisman W, van Boxtel A, Müller J. Long-term effects of drying conditions on the esential oil and color of tarragon leaves during storage. J. Food Eng. 2007; 79: 561-566.

2. Usai $\mathrm{M}$ et al. Influence of different stabilizing operations and storage time on the composition of essential oil of thyme (Thymus officinalis L.) and rosemary (Rosmarinus officinalis L.). Food Sci. Technol. 2011; LEB 44: 244-249. 


\section{DYE YIELDING MEDICINAL PLANTS IN THE CZECH COLLECTION OF GENETIC RESOURCES}

Dušek K., Dušková E., Smékalová K.

Crop Research Institute, Centre of the Region Haná for Biotechnological and Agricultural Research, Department of Genetic Resources for Vegetables, Medicinal and Special Plants, Czech Republic

Abstract

Keywords

Acknowledgements

References
Aim Some plants, primarily known for its healing effects, however, can be used also for colouring of food, fabrics, leather and other materials (Bidlová 2005). The aim of this work is to test dyeing effect of some species, which are - as a part of national inheritance - gathered in the Czech collection of genetic resources of medicinal, aromatic and culinary plants.

Material/Methods Dyeing effect of Agrimonia eupatoria (fresh flowering stems), Anthemis tinctoria (fresh and/or dry inflorescences), Calendula officinalis (fresh inflorescences), Carthamus tinctorius (dry flowers), Filipendula ulmaria (dry roots), Hypericum perforatum (fresh inflorescences), Isatis tinctoria (fresh rosette leaves), Reseda luteola (fresh flowering stems), Rubia tinctorum (dry roots), Solidago canadensis (fresh inflorescences), Symphytum officinale (fresh flowering stems, fresh roots), Tanacetum vulgare (fresh inflorescences), and so on, was tested on cotton fabric, cotton gauze, linen fabric and sheep wool yarn. Plant material was boiled in the water for several hours. After straining, the fabric or yarn was dived into the dye bath, boiled for 1 hour and then kept for 24 hours in. Different shades, intensity and/or brightness of final colours were influenced by addition of cream of tartar and/or mordant $\left(\mathrm{CuSO}_{4^{\prime}}\right.$ $\mathrm{FeSO}_{2}, \mathrm{~K}_{2} \mathrm{Cr}_{2} \mathrm{O}_{7}$ ). The resulting shade was stabilised by vinegar, dyed material was carefully rinsed and dried.

Results It was confirmed that all tested medicinal plants, actually have the ability to dye various materials. The actual colour one gets from a natural dye depends not only on the source of the dye and its volume, but also on the length of its application, the mordant and the item being dyed. A relatively huge amount of plant material is necessary to get an intensive colouration. All tested species are incorporated into the Czech collection of genetic resources of medicinal, aromatic and culinary plants in the active collection and/or working collection and gathering of new accessions (genotypes and/or species) continues. Serratula tinctoria is actually the newest acquisition.

Conclusions Plants have been used for natural dyeing since before recorded history and therefore, form a part of the cultural heritage of each nation. The species that were traditionally used for both the healing and dyeing purposes were gathered into the Czech collection of genetic resources and its dyeing ability was approved on several types of textile material.

dye yielding plants - medicinal plants - genetic resources - cultural heritage

Financial support of projects DF11P01OVV006 is gratefully acknowledged.

1. Bidlová V. Barvení pomocí rostlin. Grada Publishing, Praha, 2005. p. 86. 


\section{ACCUMULATION OF APIGENIN GLYCOSIDES IN CHAMOMILE BREEDING LINES}

Eliašová A., Fejér J., Kušnírová J.

Abstract

Keywords

Acknowledgements

References
Aim Flavone apigenin is quantitatively the most abundant flavonoid found in chamomile and contributes to the observed pharmacological properties of the drug chamomillae flos. It accumulates in the white ligulate flowers of the chamomile anthodium in a bound form as apigenin-7-O-glucoside and its various acylated derivatives (Švehlíková et al., 2004). The aim of our work was to evaluate the accumulation of apigenin flavonoids in chamomile in relation to genotype and environmental conditions.

Material/Methods Plants of four diploid breeding lines of Matricaria chamomilla L. were field-cultivated at the School garden of University of Prešov in Prešov (Slovakia) during 2 years. Apigenin derivatives were extracted from dry ligulate flowers with methanol/water solution (70/30, v/v). Extracts were analysed by HPLC/DAD/ESI+/MS.

Results On the basis of UV-visible spectra ( $\left.\ddot{e}_{\max }\right)$ and mass-to-charge ratio of the molecular ion and fragmented ion, we identified following apigenin flavonoids: apigenin aglycone, apigenin-7-O-(6"-ramnosyl)-glucoside, apigenin-7-Oglucoside together with its six mono-acylated and four di-acylated derivatives. In all breeding lines analysed, both apigenin-7-O-glucoside and apigenin-7-O-(6"-malonyl)-glucoside were the most abundant compounds. Nevertheless, we observed significant differences in the total content of apigenin flavonoids between the lines (above $30 \%$ ). In the first year of cultivation, we found significantly higher amount of the flavonoids together with significantly lower anthodium weight in all chamomile populations. We propose that the differences in precipitations and average temperature in 2 years of our investigation could influence the ontogenesis of anthodia. As was shown by Repćák and Krausová (2009), content of apigenin derivatives in chamomile depends on the inflorescence flowering phase.

Conclusions From our results, it follows that the accumulation of apigenin glycosides in chamomile may be strongly influenced by genetic as well as environmental factors. We also confirmed the previous findings of other authors that the collection and post-harvest processing of chamomile anthodia substantially affect the amount of the apigenin aglycone and apigenin-7-O-glucoside in the extracts (Schreiber et al., 1990).

Matricaria chamomilla - breeding lines - apigenin glycosides - LC/MS

The work was supported by the Agency of Ministry of Education, Science, Research and Sport of the Slovak Republic, the project ITMS: 26220120023 and 26110230069.

1. Švehlíková V. et al. Isolation, identification and stability of acylated derivates of apigenin-7-O-glucoside from chamomile (Chamomilla recutita (L.) Rauschert). Phytochemistry. 2004; 65: 2323-2332.

2. Repčák M. and KrausováT. Phenolic glucosides in the course of ligulate flower development in diploid and tetraploid Matricaria chamomilla. Food Chemistry. 2009; 116: 19-22.

3. Schreiber A. Carle R. and Reinhard E. On the accumulation of apigenin in chamomile flowers. Planta Medica. 1990; 56: 179-181. 


\title{
AMARANTH (AMARANTHUS CRUENTUS L.) - NEW VARIETY PRIBINA
}

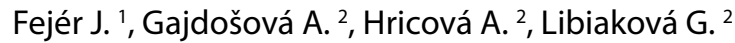

${ }^{1}$ University of Prešov in Prešov, Faculty of Humanities and Natural sciences, Department of Ecology, Prešov, Slovak Republic,

Abstract

Aim The aim of presented research is the breeding of new variety of amaranth Amaranthus cruentus $\mathrm{L}$. The alochtonous species of Amaranth and itś hybrids have perspective possibilities of utilisation in Slovakia.

Material/Methods By use of radiation mutagenesis and consecutive selection, mutant lines of Amaranthus sp. with significantly increased seed size were obtained after $\gamma$-radiation (in collaboration with Joint FAO/IAEA Programme Agency's Laboratories in Seibersdorf, Austria; Breeding and Research Station, Malý Šariš; University of Prešov and Institute of Plant Genetics and Biotechnology SAS, Nitra). The lines were characterised at morphological and biochemical levels to select the line proper for registration of new cultivar.

Results The selected mutant line of $A$. cruentus L. has increased seed size and improved nutritional value (50-70\% decreased oxalate content). Their weight of thousand seeds (WTS) is $0.9616 \mathrm{~g}$. Non-irradiated starting material genotype FICHA has WTS $0.8566 \mathrm{~g}$ (average values of the years 2011-2012, locality Prešov).

Conclusions New variety PRIBINA was registered as new variety in Slovak Central Control and Testing Institute of Agriculture on 12.11.2013.

Keywords Amaranthus cruentus L. - new variety - weight of thousand seeds (WTS)

Acknowledgements The work was supported by the Ministry of Education SR, the projectVEGA 2/0066/13:'The use of modern biotechnology in the breeding program of amaranth' and by the European Community project no 26220220180: Building Research Centre „AgroBioTech".

References $\quad$ 1. Boháč J. Šlachtenie rastlín. Príroda Bratislava; 1990; 54 - 58.

2. Fejer J. Hricová A. Libiakova G. Gajdosova A. Mutation breeding of amaranth (Amaranthus cruentus L.) - experiment results from lokality Prešov. In: 6th International conference of the European amaranth association 2012; , Neglected Under-utilized Species Research in 21st Century" - book of abstracts: 33. ISBN 978-80-970662-1-5.

3. Haban M, Feckova J, Huskja J, Illes L. Effect of amaranth genotypes on seed production and weight seeds. In Acta fytotechnica et zootechnica, 2001; Vol. 4, Spec. No.: $218-220$.

4. Gajdošová A, Hricová A, Libiaková G, Fejér J. Udelenie šlachtitel'ského osvedčenia a registrácia odrody v Štátnej odrodovej knihe. Liečivé rastliny. Láskavec metlinatý (Amaranthus cruentus L.), odroda Pribina: ev. č. 7056. Bratislava 2013: Odbor odrodového skúšobníctva Ústredného kontrolného a skúšobného ústavu polnohospodárskeho. 


\section{RESEARCH AND BREEDING OF MEDICINAL PLANTS AT THE UNIVERSITY OF PREŠOV IN PREŠOV}

Fejér J., Šalamon I., Grul'ová, D.

University of Presov in Presov, Faculty of humanities and natural sciences, Department of ecology, Presov, Slovak Republic

\section{Abstract}

Keywords

Acknowledgements

References
Aim The aim of presented research is the breeding of new varieties of chamomile (Matricaria recutita L.) and mint (Mentha $\times$ piperita L.).

Material/Methods We have bred a new variety of chamomile LIANKA using conventional methods. The method of 'the middle seedbed' was used for selection and examination of chamomile posterities of individual plants. We have bred a new variety KRISTINKA using conventional method of clonal selection.

Results A content of essential oil in the new variety of chamomile was found as $0.70 \%$. In the essential oil, the content of /-/-a-bisabolol is $55.1 \%$, chamazulene was $16.5 \%$. Quantity of /-/-a-bisabolol oxide $A$ in the essential oil was found as $1.6 \%$. The content of /-/-a-bisabolol oxide B was $2.3 \%$ (observed by gas chromatography-mass spectrometry, GC-MS method, average value years 2011-2013).

The content of essential oil in variety KRISTINKA was found as 1.38\%. It is higher than in control variety PERPETA, which has accumulated $0.93 \%$ only. KRISTINKA variety is the special chemo type with high content of menthol in essential oil $69.3 \%$. PERPETA variety has accumulated only $28.5 \%$ of menthol. Menthone was recognised as a second dominant component in the new variety of mint. Content of menthone was found as $12.5 \%$ in KRISTINKA variety, which is less than in control PERPETA variety of $39.2 \%$. The presented values are average values detected for plant samples grown in 3 years, 2011-2013 (observed by GC-MS method).

Conclusions LIANKA and KRISTINKA were registered as new varieties in Slovak Central Control and Testing Institute of Agriculture on 12.11.2013.

I-I-a-bisabolol - essential oil - Matricaria recutita L - Mentha $\times$ piperita L. - menthol

The work was supported by the European Community project nr. ITMS 26220220013: 'Using research and development for the breeding of new cultivars (prototype) of medicinal plants and their varietal registration' and nr. ITMS 26220120023 'Excellence Centre of Animals and Human Ecology'.

1. Boháč J. Šlachtenie rastlín. Príroda Bratislava; 1990; 54 - 58.

2. Fejér J, Šalamon I, Grul'ová D, Al Shammari T. Aktuálne šlachtenie rumančeka kamilkového (Matricaria recutita L.) na Prešovskej univerzite v Prešove. In: Nové poznatky z genetiky a šlachtenia polnohospodárskych rastlín. Zborník z 18. medzinárodnej vedeckej konferencie, Pieštany, 8. - 9. november 2011, 2011: 96 - 98. ISBN 978-80-89417-29-2.

3. Fejér J, Šalamon I. Breeding of German Chamomile, Matricaria recutita L., with the High Content of /-/-a Bisabolol. In: Proceedings of the 29th International Horticultural Congress 2014 (IHC2014), 17- 22 August 2014, Brisbane, Australia. Acta Horticulturae - in print.

4. Franke P, Schilcher H. Chamomile industrial profiles. CRC Press, Taylor \& Francis Group, 2005, 289 p.

5. Šalamon I, Fejér J. Udelenie šlachtitel'ského osvedčenia a registrácia odrody v Štátnej odrodovej knihe. Liečivé rastliny. Rumanček kamilkový (Matricaria recutita L.), odroda Lianka: ev. č. 7058. Bratislava 2013: Odbor odrodového skúšobníctva Ústredného kontrolného a skúšobného ústavu polnohospodárskeho, 1 p. 


\title{
THE VARIABILITY OF SECONDARY METABOLITES IN LEAVES OF MENTHA $\times$ PIPERITA CV. 'PERPETA'
}

\author{
Fialová S., Tekel'ová D., Grančai D.
}

Comenius University in Bratislava, Faculty of Pharmacy Department of Pharmacognosy and Botany, Slovak Republic

Abstract

Keywords

References
Aim Mentha x piperita (L.) Huds., the species of the genus Mentha L. from the family Lamiaceae, has a dominant position over a wide area of medicinal plants used in therapy of different disorders, especially gastrointestinal. This plant has a high commercial significance due to its use in pharmaceutical, cosmetic and food industry (Lawrence, 2007).

This work deals with the fluctuation of essential oil (EO) compounds and phenolic compounds in leaf pairs of peppermint.

Methods The leaf pairs from 1 (top) to 10 (basal) were separated from the plants after drying. The isolation of EO was performed by ultrasonication using dichloromethane. EO compounds were identified and their relative contents were evaluated by gas chromatography mass spectroscopy. The contents of total hydroxycinnamic derivatives (THD) expressed as rosmarinic acid (Arnow reagent, $\lambda=505 \mathrm{~nm}$ ) and flavonoids expressed as luteolin-7-O-glucoside ( $\mathrm{AlCl}_{3^{\prime}}$ $\lambda=392 \mathrm{~nm}$ ) were determined by spectrophotometric methods described in European Pharmacopoeia $8^{\text {th }}$ edition. The content of rosmarinic acid in different leaf pairs was measured using high performance liquid chromatography. Results It is known, that EO compounds of peppermint, particularly menthol, menthone, menthofuran and menthyl acetate influence its quality. We recorded a descendant character of menthone and menthofuran in basipetal direction. The higher content of both reduces the quality of EO. Otherwise, ascendant character in basipetal direction was detected in menthol and menthyl acetate, high EO quality indicators. Our results correspond with investigations of Brun et al. (1991) and Rohloff (1999) on peppermint (Brun et al., 1991; Rohloff, 1999). The variability of phenolic compounds in peppermint during specific time period has been examined before (Fialová et al., 2014; Fialová et al., 2015). But there is only little known about the variability of polar phenolic compounds in different leaf pairs of M. $\times$ piperita (Voirin and Bayet 1992). We determined the content of THD in leaves to range from 6.8 to $12.4 \%$, of which 1.6 up to $3.1 \%$ presents as rosmarinic acid. The content of flavonoids expressed as luteolin-7-O-glucoside varied from 0.8 up to $1.8 \%$. The highest contents of THD, rosmarinic acid as well as flavonoids were detected in apical leaves.

Conclusions We can conclude ascendant character of the quality of EO in peppermint leaves in basipetal direction, while the contents of phenolic compounds increase acropetally.

Mentha x piperita - essential oil - hydroxycinnamic derivatives - rosmarinic acid - flavonoids

1. Brun N, Colson M, Perrin A, Voirin B. Cheical and morphological studies of the effects of ageing on monoterpene composition in Menthe x piperita leaves. Can J Bot. 1991.; 69:2271-78.

2. Fialová S, Tekel'ová D, Švajdlenka E, Potúček P, Jakubová K, Grančai D. The variability of secondary metabolites in Mentha $\times$ piperita cv. 'Perpeta' during the development of inflorescence. Acta Fac Pharm Univ Comen. LXI, 2014 (2): 21-25.

3. Fialová S, Tekel'ová D, Rendeková K, Klinčok J, Kolárik M, Kurucová K, Grančai D. Phenolic compounds variation in Mentha L. species in the course of a four-years period. Acta Fac Pharm Univ Comen. 2015 [in press].

4. Lawrence BM. Mint. The genus Mentha. Boca Raton, London, New York: CRC Press, Taylor \& Francis Group; 2007.

5. Rohloff J. Monoterpene compostition of essential oil from peppermitn (Mentha x piperita L.) with regard to leaf position using solid-phase microextaction and gas chromatography/mass spectometry analysis. J. Agric. Food Chem. 1999; 47:3782-3786.

6. Voirin B, Bayet CH. Developmental variations in leaf flavonoid aglycones of mentha x piperita. Phytochemistry. 1992; 31(7):2299-2304. 


\title{
TOTAL PHENOLIC CONTENT AND TOTAL ASCORBIC ACID DETERMINATION IN SEVERAL VARIETIES OF FRESH BASIL (OCIMUM BASILICUM L.)
}

\author{
Fogašová E., Neugebauerová J.
}

Mendel University in Brno, Faculty of Horticulture, Department of Vegetable Growing and Floriculture, Czech Republic

Abstract

Keywords

References
Aim Sweet basil (Ocimum basilicum L.) is a herbaceous plant, which originates from India, Africa and South Asia. In many countries of the world, it is grown as a spice, medicinal and aromatic plant (Hiltunen, Holm, 1999). There is enormous variability of cultivars and hybrids, which provides many chemotypes and different composition of contained compounds (Zheljazkov et al., 2008). Their quality and quantity is affected by many influences (Loughrin and Kasperbauer, 2010). Especially interesting are red-leaved varieties, which contain antocyanins, that might increase phenols and antioxidant capacity in basil (Landi et al., 2013).

Material/Methods The experiment started in 2014 in the area of FH MENDELU Lednice, Czech Republic. Used varieties of $O$. basilicum L. from SEMO Smržice company were: 'Purple Opal', 'Red Rubin','Mammolo Genovese','Dark Green','Lettuce Leaf' and 'Ohře'(the control, obtained from SEVA Seed Company). Plants were cultivated in April in greenhouse and were planted in May in the field, $0.3 \times 0.5 \mathrm{~m}$, planted were 80 plants of each variety.

Total phenolic content (TPC) was determined by the Folin-Ciocalteu method (results expressed in $\mathrm{mg} \mathrm{GAE} 100 \mathrm{~g} \mathrm{~g}^{-1} \mathrm{dw}$ ) and ascorbic acid was determined by high-performance liquid chromatography, the HPLC method (results expressed in $\mathrm{mg} \cdot \mathrm{kg}^{-1} \mathrm{fw}$ ).

Results TPC ranged from 2520.35 to $6525.34 \mathrm{mg} \mathrm{GAE} .100 \mathrm{~g}^{-1} \mathrm{dw}$. The highest average amount was $5451.81 \mathrm{mg}$ GAE.100 g ${ }^{-1} \mathrm{dw}$ measured in 'Purple Opal'. The lowest average amount was $3556.52 \mathrm{mg} \mathrm{GAE} .100 \mathrm{~g}^{-1} \mathrm{dw}$ measured in 'Mammolo Genovese'. The amount of ascorbic acid ranged from $82.78 \mathrm{mg}^{-\mathrm{kg}^{-1} \mathrm{fw}}$ to $222.07 \mathrm{mg} \cdot \mathrm{kg}^{-1} \mathrm{fw}$. The highest average amount was $188.28 \mathrm{mg} \cdot \mathrm{kg}^{-1} \mathrm{fw}$ measured in 'Mammolo Genovese' and the lowest average amount was $85.41 \mathrm{mg} \cdot \mathrm{kg}^{-1} \mathrm{fw}$ measured in 'Lettuce Leaf"

Conclusion The content of phenolic substances and ascorbic acid is affected by variety. The red-leaved varieties have more phenols than the green-leaved ones. Varieties with high concentration of phenols have also high amount of ascorbic acid. The red-leaved varieties of basil might have higher antioxidant capacity than the green-leaved ones.

basil - phenols - ascorbic acid - variety

1. Hiltunen R and Holmy Basil, The genus Ocimum. Helsinki: Harwood academic Publishers. 1999; 167 p. ISBN 90-5702432-2.

2. Zheljazkov VD et al. Yield and composition of O. basilicum L. and O. sanctum L. grownatfourlocations. In Journal of Agriculture Food Chemistry, 2008; 43/3. ISSN 2320-3862.

3. Loughrin JH and Kasperbauer MJ. Lightreflectedfromcoloredmulchesaffects aroma and phenolcontent of sweetbasil (O. basilicum L.) leaves. Bragantia. 2010. ISSN 0006-8705.

4. Landi M, Pardossi A, Remorini D and Guidi L. Antioxidant and photosynthetic response of a purple-leaved and green-leavedcultivar of sweetbasil (O.basilicumL.) to boronexcess. Environmental and Experimental Botany 2013; 85: 64-75. 


\title{
PHARMACOGNOSTICAL INVESTIGATION OF GENUS CORNUS LEAVES
}

\author{
Forman V. ${ }^{1}$, Ficková M. ${ }^{2}$, Bukovský M. ${ }^{3}$, Šeršeň F. ${ }^{4}$, Grančai D. ${ }^{1}$
}

${ }^{1}$ Comenius University in Bratislava, Faculty of Pharmacy Department of Pharmacognosy and Botany, Slovakia ${ }^{2}$ Slovak Academy of Sciences, Institute of Experimental Endocrinology Laboratory of Cell Endocrinology, Slovakia ${ }^{3}$ Comenius University in Bratislava, Faculty of Pharmacy Department of Cellular and Molecular Biology of Drugs, Slovakia ${ }^{4}$ Comenius University in Bratislava, Faculty of Natural Sciences Institute of Chemistry, Slovakia

Abstract

Keywords

Acknowledgements

References
Previously, there have been quantified selected groups of secondary metabolites of Cornus species at the Department of Pharmacognosy and Botany, Faculty of Pharmacy.

Aim The aim of our research is the investigation of Cornaceae leaves. In some countries (Turkey, etc.), people drink tea prepared from them. But, there is still little information about their chemical composition and biological effects.

Results We have tested the antiproliferative, immunomodulatory, antimicrobial (against E. coli) and antioxidative activity of water infusions prepared from the freeze-dried leaves of Cornus officinalis, C. kousa, C. sericea 'Flaviramea', C. mas, C. coreana and C. alba in vitro.

The most potent species are C. officinalis (antiproliferative and antioxidative), C. coreana (immunomodulatory), C. mas (antimicrobial). C. officinalis leaves are also being studied for their chemical composition. Currently, isolation and identification of polar substances is being carried out.

Conclusions Genus Cornus appears to be prospective in the current trend of searching for new natural drug sources.

Cornaceae - leaves - biological activities - chemical composition

This project was supported by the Faculty of Pharmacy grant FaF UK/7/2015.

1. Forman V, Haladová M, Grančai D. Quantification of some secondary metabolites in selected Cornaceae species. Acta Fac. Pharm. Univ. Comen. LXII. 2015; (SupplIX) in press.

2. Celep $\mathrm{E}$, Aydin A, Kirmizibekmez $\mathrm{H}$, Yesilada E. Appraisal of in vitro and in vivo antioxidant activity potential of cornelian cherry leaves. Food Chem Toxicol. 2013;62:448-455.

3. Daeyoung K, Kwang-Kyun P, Sang Kook L, Seung-Eun L, Jae-Kwan H. Cornus kousa F. Buerger ex Miquel increases glucose uptake through activation of peroxisome proliferator-activated receptor and insulin sensitization. J Ethnopharmacol. 2011;133:803-809.

4. Šeršeň $F$, Mučaji $P$, Grančai $D$, Nagy $M$. Antioxidative properties of methanol extracts from leaves and fruits of Ligustrum vulgare L. Acta Fac. Pharm. Univ. Comen. LII. 2005; 204-209.

5. Jancová $M$, Urbančíková B, Šeršeň $F$, Haladová $M$, Eisenreichová $E$, Bukovský $M$, Grančai D. Immunomodulatory effects and antioxidant activity exhibited by Holodiscus discolor (Pursh) Maxim. infusions. Acta Fac. Pharm. Univ. Comen. LVII. 2010; 41-46. 


\title{
THE INFLUENCE OF METHOD AND TIME OF HARVEST ON CHAMOMILE
}

\author{
Francuski E. ', Adamović D. ', Jaćimović G. ', Latković D. ', Marinković B. ', Crnobarac J.'
}

${ }^{1}$ University of Novi Sad, Faculty of Agriculture, Novi Sad, Serbia ${ }^{2}$ Institute of field and vegetable crop, Novi Sad, Serbia

\section{Abstract}

Keywords

Acknowledgements

References
Aim The common chamomile (Chamomilla recutita L. Rauschert) is one of the oldest, most favoured and much used medicinal plant throughout the world, grown primarily for the flowers, which are used as a drug. The harvesting process substantially influences the quality of raw flower material. Stem rests remaining on the flower heads have to be as short as possible and other constituents, such as leaves or insect or soil rests should be avoided (Brabandt et al., 2011). High quality is achieved by hand picking; however, the amount of harvested material per hour is very low (3-5 $\mathrm{kg} \mathrm{h}^{-1}$ ) compared to specific picking machines with $18 \mathrm{~kg} \mathrm{~h}^{-1}$ (Ehlert et al., 2011). Because large-scale production can be realised only by mechanisation of the harvesting, we compare it to manual harvest.

Material/Methods Split plot field trial was conducted in the Institute of Field and Vegetable Crops in Novi Sad. There were three harvest times: around May 10, 20 and 30 and two harvesting methods: manual hand picking and with specific picking machines (Martinov et al., 1992). We measured moisture and impurity of flowers and natural and final (without impurity) yield of fresh flower in $\mathrm{kg} \mathrm{ha}^{-1}$

Results According to F test, significant effect on all traits was of harvest time, while harvest method only affected on impurity. Only significant interaction effect was on moisture. Harvest time partitioning in total treatments sum squares for moisture, impurity, natural and final yield were $85,77,79$ and $81 \%$, respectively. Moisture content in flower significantly decreases by harvest time from 82.9 to $80.4 \%$. The lowest impurity was in second harvest (2.8\%) and on average for manual harvesting was significantly lower, difference was $5.8 \%$. The highest fresh natural and final flower yield was in second harvest, 6015 and $5840 \mathrm{~kg} \mathrm{ha}^{-1}$, respectively. Third harvest was significantly lower, while between first and second harvest, differences were not significant. Although, between harvest methods, there were no significant differences; final flower yield of hand picking was higher for $421 \mathrm{~kg} \mathrm{ha}^{-1}$ than machine harvesting. Conclusions Harvest time had more influence than harvest method on all traits. According to yield and impurity in flowers, optimal was second harvest (May 10). There was no significant yield difference in harvesting method because of improvement in construction of harvesting machine.

Chamomile - harvest method and time - moisture - impurity - fresh flower yield

This study is a part of the project TR31025 funded by the Serbian Ministry of Education, Science and Technological Development.

1. Martinov M, Tesic M and Müller J. Erntemaschine für Kamille. Landtechnik, H. 1992; 10: 505-507.

2. Brabant $\mathrm{H}$ and Ehlert D. Chamomile harvesters: A review. Industrial Crops and Products, 2011.34: 818-824

3. Ehlert D, Adamek R. Giebel A, Horn HJ. Influence of comb parameters on picking properties for chamomile flowers (Matricaria recutita). Industrial Crops and Products. 2011;33:242-247. 


\section{YEARS OF THE SECTION ON NATURAL DRUGS OF SLOVAK PHARMACEUTICAL SOCIETY ACTIVITY}

Grančai D.

Comenius University in Bratislava, Faculty of Pharmacy

Department of Pharmacognosy and Botany, Slovakia

Thstract
The Section on Natural Drugs is one of the sections of the Slovak Pharmaceutical Society. The section was established
in the year 1995 with the aim to mediate progress in the field of Pharmacognosy, pharmacoergasy and healing with
medicinal plants. Information collection, completion of the results of research and natural drugs application are its
main activities. The members are informed about latest knowledge during section work days.
The section activity of the Society is focussed on the following topics:
- obtaining forms of substances from natural resources (cultivation, collecting and adjustment of plant material,
isolation of natural substances)
- chemical analysis of substances in drugs
- study of biological activities
- new trends in natural drug research
- development of new phytotherapeutics on the basis of standardised plant extracts
- phytotherapeutics and dietary supplements in Slovak market
- legislation and valid laws for medicinal plants (Ph. Eur., SFK)
This lecture deals with 20-year existence of the Section on Natural Drugs of the Slovak Pharmaceutical Society.
Section on Natural Drugs - Slovak Pharmaceutical Society - 20 years 


\title{
THE CONCENTRATION OF PHENOLICS SUBSTANCES IN SOME SPECIES OF ASTERACEAE FAMILY
}

\author{
Habán M. ${ }^{2}$, Kobida L.. ', Kobidová R. ${ }^{1}$, Habánová M. ${ }^{3}$, Macák M. ${ }^{1}$ \\ ${ }^{1}$ Slovak University of Agriculture in Nitra, Faculty of Agrobiology and Food Resources, \\ Department of Sustainable Agriculture and Herbology, Slovakia \\ ${ }^{2}$ Comenius University in Bratislava, Faculty of Pharmacy Department of Pharmacognosy and Botany, Slovakia \\ ${ }^{3}$ Slovak University of Agriculture in Nitra, Faculty of Agrobiology and Food Resources, \\ Department of Human Nutrition, Slovakia
}

\section{Abstract}

Keywords

Acknowledgements

References
Aim The Asteraceae family is one of the largest families of flowering plants consisting of approximately 1600 genera and over 23,000 species (Bohm and Stuessy, 2001). Asteraceae species has been used for centuries as a medicinal plant mostly for its anti-inflammatory, analgesic, antimicrobial, antispasmodic and sedative properties. They contain antioxidant substances as polyphenolics acids (Vaverková et al., 1997, 2007). The aim of this study is to assess the concentration of phenolic acids in five Asteraceae species for their chemical composition.

Material/Methods Plants of Asteraceae species (Echinacea purpurea, Echinacea angustifolia, Artemisia dracunculus, Calendula officinalis and Achilea millefolium) were field cultivated in Kolíñany and Nitra during 2 years. An analysis procedure was similar to Lin and Harnly (2012), with little change. Phenolic acids were extracted from dry plants with methanol/water solution $(60 / 40, v / v)$. Extracts were analysed by WATERS BREEZE high-performance liquid chromatography, HPLC.

Results On the basis of UV visible spectra and retention time and comparing them with authentic standards, we analysed the following phenolic acids: rutin, quercetine, rosmarinic acid and caffeic acid. Level of phenolic acids $\left(\mathrm{mg} . \mathrm{kg}^{-1}\right)$ was: rutin - Echinacea purpurea (504,8-585.3), E. angustifolia (545.6-743.67), Artemisia dracunculus (684.2794.6), Calendula officinalis (469.5-1235,2), Achilea millefolium (101.3-147.7), rosmarinic acid - E. purpurea (40.43-122.7), E. angustifolia (17.15-24,3), A. dracunculus (37.55-134.02), C. officinalis (82.9-90.6), A. millefolium (384.3-475.9), quercetin was from 0.2 (E. angustifolia) to $210.7 \mathrm{mg} \cdot \mathrm{kg}^{-1}$ (A. dracunculus), caffeic acid from 123.5 (A. dracunculus) to $719.7 \mathrm{mg} \cdot \mathrm{kg}^{-1}$ (E. purpurea).

Conclusion In the present work, an HPLC method has been developed and applied for the identification and characterisation of active phenolic components in Asteraceae species. The data presented in this report indicate high level of phenolic acids in five Asteraceae plants for rutin $1235.24 \mathrm{mg} \cdot \mathrm{kg}^{-1}$ - C. officinalis, and caffeic acid - $719.7 \mathrm{mg} \cdot \mathrm{kg}^{-1}$ in E. purpurea.

Asteraceae - phenolic acids - HPLC

The work was supported by VEGA project No. 1/0544/13 and VEGA project No. 1/0127/14.

1. Bohm BA and Stuessz TF. Flavonoids of the sunflower family. Springer-Verlag/Wien, Austria, 2001; 831 p. ISBN 9783-7091-6181-4

2. Lin LZ and Harnly M. Quantitation of Flavanols, Proanthocyanidins, Isoflavones, Flavanones, Dihydrochalcones, Stilbenes, Benzoic Acid Derivates Using Ultraviolet Absorbance after Identification by Liquid Cromatography-Mass Spectrometry. J. Agric. and Food Chemistry. 2012. 60: 5832-5840

3. Vaverková Š, Mistríková I, Hollá M, Gromová Z, Habán M, Labat R. Essential oil variability in different Echinacea species. med. Plant Rep. 1997; 4: 66-69. ISSN 0354-5830.

4. Vaverková Š, Mikulášová M, Habán M, Tekel' J, Hollá M, Otepka P. Variability of the essential oil from three sorts of Echinacea Moench genus during ontogenesis. Čes. slov. Farm. 2007; 56: 121-124, ISSN 1210-7816. 


\title{
THE EVALUATION OF DIFERENTIAL CULTIVARS AND PRODUCTS OF SILYBUM MARIANUM
}

\author{
Habán M. ${ }^{1,2}$, Luščáková D. ${ }^{2}$, Vaverková S. ${ }^{1}$, Kobidová R. ${ }^{2}$ \\ ${ }^{2}$ Comenius University in Bratislava, Faculty of Pharmacy, \\ Department of Pharmacognosy and Botany, Slovakia \\ ${ }^{2}$ Slovak University of Agriculture in Nitra, Faculty of Agrobiology and Food Resources, \\ Department of Sustainable Agriculture and Herbology, Slovakia
}

Abstract

Keywords Silybum marianum - achenes - silymarin complex - pharmaceutical quality

Acknowledgements This paper was supported by the Scientific Grant Agency VEGA of The Ministry of Education of the Slovak Republic and

Slovak Academy of Sciences, Grant No. 1/0544/13.

References

Aim Milk thistle is a popular herbal plant nowdays. The medicinal substance, silymarin is produced from seed shells (Wierzbowska, 2014). Silymarin is a complex of flavonolignans (silybin, silychristin, silydianin, isosilybin) (Andrzejewska and Sadowska, 2008). The major medicinal activities of Silybum are anticancer, antidepressant, antioxidant, cardio protective, demulcent, digestive tonic, hepatoprotective, hepatoregenerative, immunostimulatory and as a neuroprotective (Sidhu and Saini, 2012).

Material/Methods In laboratory, experiment with Silibi mariani fructus were proven to be a fraction of silymarin complex:silychristin, silydianin, silybin A, silybin B, isosilybin A, izosilybin B. Eight samples were examined: 1. Silyb (Czech Republic) grown at Dolná Malanta (Nitra, Slovakia), 2. Silyb grown in Šumperk (Czech Republic), 3. Mirel (Czech Republic), 4. Silma (Poland), 5. Control (unknow origin). The benchmarks were tablets 6. LAGOSA (Germany), 7. FLAVOBION (Czech Republic) and 8. Milk thistle loose tea (Slovak Republic).

Results In the observed samples were found differences between the various fractions of silymarin complex on which we can recognise silybin and silydianin forms. The content of silybin $\left(\mathrm{mg}^{\left.-\mathrm{g}^{-1}\right)}\right.$ in the samples was as follows: 1. 8744.612,206.0; 2. 10,674.1-12,365.7; 3. 9295.3-11,018.6. 4. 8592.8-12,506.2; 5. 1874.0-2896.0 compared to benchmark 6. 4990.2-5082.2; 7. 4798.1-4824.2; 8. 673.5-1059.0. The silydianin content $\left(\mathrm{mg}^{-\mathrm{g}^{-1}}\right)$ in the samples fluctuated as follows: 1. 1770.7-2053.0; 2. 1926.1-2901.7; 3. 1659.9-1864.9; 4. 3966.7-5654.9; 5. 6048.0-7378.2; compared to benchmark 6. 2447.5-2606.4; 7. 1921.1-1936.7; 8. 100.0-134.5.

Conclusions Based on the results, it is recommended to continue the research of the quality parameters of milk thistle achenes in the following years.

1. Wierzbowska J. Effect of fertilization on the content of the macronutrients in fruits of milk thistle (Silybum marianum L. Gaertn.). J. Elem. 2014: 723 - 732.

2. Andrzejewska J, Sadowska K. Effect of the cultivation conditions on the variability and the interrelation of the yield and raw material quality in milk thistle (Silybum marianum (L.) Gaertn.). Acta Sci. Pol. Agricultura, 2008; vol 7 (3): $3-11$.

3. Sidhu MC and Saini P. Silybum marianum: a plant of high medicinal importance - a review. World Journal of Pharmaceutical Research, 2012; vol. 1: $72-86$. 


\title{
PRODUCTION OF MILK THISTLE IN SLOVAK REPUBLIC
}

\author{
Habán M. ${ }^{2}$, Luščáková D. ${ }^{1}$, Macák M. ${ }^{1}$, Kobidová R. ${ }^{1}$, Vaverková Š. ${ }^{2}$ \\ ${ }^{1}$ Slovak University of Agriculture in Nitra, Faculty of Agrobiology and Food Resources, \\ Department of Sustainable Agriculture and Herbology, Slovakia \\ ${ }^{2}$ Comenius University in Bratislava, Faculty of Pharmacy, \\ Department of Pharmacognosy and Botany, Slovakia
}

Abstract

Keywords

Acknowledgements

References
Aim Milk thistle is annual to biennal medicinal plant (1) from the Asteraceae family (2). The fruits are black, shiny achenes, 5-7 mm long (3). In the years 2013 and 2014, milk thistle has been the most cultivated medicinal plant in Slovakia (4).

Material/Methods In this field experiment is used variety of milk thistle named Silyb. Polyfactorial field experiment was established and experimentally controlled during the vegetation period of the years 2012-2014. The experiment was arranged in one independent block. Plant material was harvested in the ontogenetic stage of the achenes ripening. Harvesting was done with adapted combine harvester.

Results The highest yields of milk thistle fruits was measured $745.0 \mathrm{~kg}^{-\mathrm{ha}^{-1}}$ (KMF, 2013 variant - no crop residues, with intercrop, with fertilisation), which was statistically determined. The impact of growing year on yield milk thistle achenes confirmed the high variability of yields. Yields obtained in 2013 was statistically significantly different from the rest of the tested years. On yield of milk thistle achenes, we confirmed highly significant effect of year and fertilisation, and inconclusive impact of sowing intercrop and plowing crop residues.

Conclusions Based on the 3-year results, it is recommended to continue the research of the production parameters of milk thistle yields in following growing seasons.

Silybum marianum - yield - intercrop - fertilisation - crop residues

This paper was supported by the Scientific Grant Agency VEGA of The Ministry of Education of the Slovak Republic and Slovak Academy of Sciences, Grant No. 1/0544/13: The research of agro-enviromental indicators of sustainability and production capability of agro-ecosystem by diversification of crop rotation pattern in changing climate.

1. Young JA, Evans RA, Hawkes RB. Milk thistle (Silybum marianum) seed germination. Weed Science. 1978; 26:395-398. 2. Cwalina-Ambroziak B, Wierzbowska J, Damszel M, Bowszys T. The effect of mineral fertilization on achenes yield and fungal communities isolated from the stems of milk thistle (Silybum marianum (L.) GAERTNER). Acta Sci. Pol. Hortorum Cultus 2012; 11(4:157-168.

3. Andrezejewska J, Sadowska K, Mielcarek S. Effect of sowing date and rate on the yield and flavolignan content of the fruits of milk thistle (Silybum marianum L. Gaertn.) on light soil in a moderate climat. Industrial Crops and Products. 2011; 33:462-468. 


\title{
EFFECT OF BERGENIA EXTRACTS ON MESOCESTOIDES VOGAE
}

\author{
Hendrychová H. ${ }^{\prime}$, Hrčková G. ${ }^{2}$, Velebný S. ${ }^{2}$, Tůmová L. ${ }^{1}$ \\ ${ }^{1}$ Charles University in Prague, Faculty of Pharmacy in Hradec Králové, \\ Department of Pharmacognosy, Czech republic \\ ${ }^{2}$ Parasitological Institute of the Slovak Academy of Sciences Košice, Slovakia
}

Abstract

Keywords

Acknowledgements

References
Aim Bergenia genus, family Saxifragaceae, is a traditional source of healing compounds in Asian countries such as India, Nepal, Bhutan, Russia or China. Individual parts of plant demonstrate interesting biological activity, antioxidant, anti-inflammatory, antiulcer, anticancer, antidiabetic or cytoprotective effect. Bergenia is a valuable resource of interesting chemical compounds. This plant contains several active constituents such as polyphenol bergenin (C - glucoside of 4-O-methyl gallic acid), its derivative norbergenin and catechin. The main attention is focussed on bergenin for its antiviral, antibacterial and antioxidant effect. Another active compound of this species is arbutin, phenolic monoglucoside of hydroquinone. The main aim of our study is to reveal the influence of natural biological substances on the viability of larval stage of Mesocestoidesvogae.

Material/Methods Our scientific research was focussed on the effects of in vitro exposure of chemically pure substances of bergenin and arbutin $(25-200 \mu \mathrm{g} / \mathrm{ml})$ on the surface morphology, motility, viability and metabolic activity on intact larval stage of Mesocestoidesvogae. The similar influence of different plant extracts of Bergenia crassifolia, $B . \mathrm{x}$ ornata and B. ciliata $(1 \mathrm{mg} / \mathrm{ml})$ was also tested. For the determination of metabolic activity, MTT assay was used. It allows to determine the influence of substances on the basal larvae metabolism (respiratory chain). Similar tests were used for monitoring the effect of different matters on the viability and metabolic activity (reactive formation of oxygen molecules) in mammalian cells. Examination of treated larvae showed an effect that was concentration and timedependent.

Results Bergenin caused higher larval activity in anaerobic conditions immediately after addition to the medium of larvae. After 24 hours, the activity decreased. Very similar activity of larvae showed also with arbutin. Arbutin most significantly affected surviving larvae at concentration of $200 \mu \mathrm{g} / \mathrm{ml}$. From all tested Bergenia extracts, the most intensive influence had B. crassifolia.

Conclusion Test of all natural substances revealed proven positive effect on the overall viability and motility of the larvae. All tested natural substances affect on receptors, respiratory metabolism and oxidative stress of larvae and contribute them their proven antioxidant effect. The exact mechanism of action is subject to further research.

Bergenia - Mesocestoidesvogae - metabolic activity

Acknowledgements to Zentiva company for providing financial contribution that helped to realise this research and SVV 260186

1. Hendrychová H., Tůmová L., Rod Bergenia - obsahové látky a biologická aktivita. Čes. Slov. Farm. 2012; 61 (5): 203-209.

2. Ferrari M, Fornasiero MC, Isetta AM. MTT colorimetric assay for testing macrophage cytotoxic activity in vitro. Journal of Immunological Methods, 1990; 131: 165-172. 


\title{
PHYTOCHEMICAL STUDY OF INDIVIDUAL PLANT SPECIES OF BERGENIA GENUS
}

\begin{abstract}
and Indian traditional medicine. These species have been used for centuries in therapy of various diseases. They have demonstrated antioxidant, antibacterial, antiviral, immunostimulant, anti-inflammatory, anticancer, antidiabetic, antitussive, hepatoprotective and diuretic effects. The main aim was to determine the content of secondary metabolites in three taxons of Bergenia genus - Bergenia crassifolia (L.) Fritsch, Bergenia ciliata (Haw.) Sternb. a Bergenia x ornata Stein., to compare their biological activities and to identify the most appropriate kind of Bergenia plants with the greatest potential for use in therapy. Plant hybrid B. $x$ ornata was evaluated on the content of phenolic compounds and biological activity for the first time.

Material/Methods The contents of arbutin, total polyphenols, anthocyanins and bergenin (in mg.g-1 of dry weight) were determined in the extracts of green and red leaves of Bergenia plants. Bergenia leaf extracts were tested for antioxidant, antiradical, tyrosinase, antiparasitic, immunostimulating, anti-platelet activity and its ability to inhibit the enzyme COX-1 and the formation of PGH2.

Results The highest content of phenolic glycoside arbutin, total polyphenols, bergenin in the leaves of B. crassifolia and $B . x$ ornata was found. The anthocyanins were also determined. Ethanol extracts of Bergenia proved the ability to inhibit the activity of mushroom tyrosinase. Antiparasitic activity was tested on the larvae of Mesocestoides vogae. Larvicidal activity of bergenin, arbutin and Bergenia extracts has not been established. Lymphocytes were markedly activated (as measured by CD69 expression) by ethanolic extracts of B. $x$ ornata, as revealed in the imunostimulatory assay. Antiplatelet activity was proved for bergenin and aqueous extract of $B$. $x$ ornata, which siginificantly reduced the platelet aggregation up to $28,53 \%$ and was effective in analogy with acetylsalicylic acid $(24,17 \%)$. The same extract was active in the inhibition of cyclooxygenase (COX-1).

Conclusions The content of secondary metabolites in Bergenia leaf extracts was correlated significantly with the meteorological data. Significant positive correlations between phenolic contents and results from the measurement of antioxidant activity were demonstrated. Bergenia extracts proved their biological activity in all tested assays. B. crassifolia and B. $x$ ornata have a great potential for use in therapy.
\end{abstract}

Abstract

Aim Bergenia, native to central Asia, is promising source of medicinal compounds mainly in the system of Chinese

Keywords

Acknowledgements

References
Bergenia - secondary metabolites - biological activity

Výzkum byl podpořen Specifickým vysokoškolským výzkumem SVV 260186.

1. Hendrychová, H.; Martin, J.; Tůmová, L.; Kočevar-Glavač N. Bergenin content and free radical scavenging activity of Bergenia extracts. Natural Product Communications. 2015, 10(7), 1273-1275.

2. Hendrychová, H.; Vildová, A.; Kočevar-Glavač, N.; Tůmová, L.; Abdykerimova-Kanybekovna, E.; Tůma J. Antioxidant activity and phenolic content of Bergenia crassifolia, B.x ornata and B. ciliata. Natural Product Communications. 2014, 9(4), 445-596. 


\title{
THE ROLE OF LIPOXYGENASE IN ELICITOR-INDUCED SANGUINARINE PRODUCTION IN PAPAVER SOMNIFERUM L. SUSPENSION CULTURES
}

\author{
Holková I., Balažová A., Bilka F., Bilková A., Bezáková L. \\ Comenius University in Bratislava, Faculty of Pharmacy Department of Cellular \\ and Molecular Biology of Drugs, Kalinčiakova 8, SK-832 32, Bratislava, Slovakia
}

Abstract

Keywords

Acknowledgements

\begin{abstract}
Aim Opium poppy (Papaver somniferum L.) suspension cultures were treated with abiotic elicitors - methyl jasmonate (MJ) and salicylic acid (SA) to determine the role of lipoxygenase enzyme (LOX, EC 1.13.11.12) in sanguinarine production. Different concentrations and periods of action of the elicitors were tested. Some biochemical features of LOX were also investigated.

Material/Methods LOX activity was determined by spectrophotometric method at $234 \mathrm{~nm}$ and expression of LOX proteins was monitered by Western blot analysis. Sanguinarine content was analysed using thin layer chromatography and determined by luminescence spectrophotometer at $324 \mathrm{~nm}$ of excitation and $408 \mathrm{~nm}$ of emission wavelengths. Results $P$. somniferum suspension cultures responded to elicitor treatment with strong and transient increase of LOX activity followed by sanguinarine accumulation. LOX activity increased in elicited cultures, especially at $24 \mathrm{~h}$ after $\mathrm{MJ}$ and SA application. Sanguinarine accumulated to maximal levels of $169.5 \pm 31.2 \mu \mathrm{g} \cdot \mathrm{g}^{-1}$ dry cell weight at $48 \mathrm{~h}$ after challenged with MJ and $284.4 \pm 52.5 \mu \mathrm{g} \cdot \mathrm{g}^{-1}$ dry cell weight in SA-treated cultures in comparison with control samples (20.7 $\pm 12.5 \mu \mathrm{g} \cdot \mathrm{g}^{-1}$ dry cell weight). SDS/PAGE and Western blotting analysis confirmed that LOX expression was induced by application of MJ or SA in opium poppy suspension cultures. The relative molecular mass of the opium poppy LOX was determined to be $85 \mathrm{kDa}$.

Conclusions The obtained results indicate that sanguinarine production in opium poppy suspension cultures is associated with the activity of LOX and demonstrate that LOX enzyme participates in the signalling pathway, which can affect the biosynthesis of sanguinarine.
\end{abstract}

Papaver somniferum - lipoxygenase - elicitation - sanguinarine

The research was supported by APVV-0484-12 and FaF UK/17/2013. 


\title{
INHIBITORY POTENTIAL OF BENZOPHENANTHRIDINE ALKALOIDS AGAINST CYCLOOXYGENASE
}

\author{
Hribova P. ${ }^{1}$, Navratilova S. ${ }^{1}$, Hosek J. ${ }^{2}$ \\ ${ }^{1}$ University of Veterinary and Pharmaceutical Sciences Brno, Faculty of Pharmacy, \\ Department of Natural Drugs, Czech Republic \\ ${ }^{2}$ University of Veterinary and Pharmaceutical Sciences Brno, Faculty of Pharmacy, \\ Department of Molecular Biology and Pharmaceutical Biotechnology, Czech Republic
}

\begin{abstract}
Aim Acute and chronic inflammation is a complex process that can be induced by a variety of causes. Anti-inflammatory agents act through a spectrum of very different modes of action (Ramprasath, 2004). Non-steroidal anti-inflammatory agents provide analgesic, antipyretic and, in higher doses, anti-inflammatory effect. However, their use is associated with frequent side effects. Natural compounds can serve as a source of new anti-inflammatory agents, for they are easy to obtain and relatively free of side effects (Bekhit, 2008; Sharma, 2010).

Material/Methods In the screening of new anti-inflammatory compounds, cyclooxygenase (COX) and lipoxygenase (LOX) inhibition is widely employed. Therefore, COX-1 and COX-2 inhibition assays were used to evaluate the antiinflammatory effect of seven benzophenanthridine alkaloids in this study.

Results Macarpine at a final concentration of $150 \mu \mathrm{M}$ showed considerable potential to inhibit COX-2 with the IC value of $148.1 \mu \mathrm{M}$. The results also demonstrated that macarpine preferentially inhibited COX-2 rather than COX-1. Other compounds at a concentration of $150 \mu \mathrm{M}$ were inactive or showed an insignificant inhibitory potential.

Conclusions It cannot be unequivocally concluded that benzophenanthridine alkaloids are potentially promising anti-inflammatory compounds, although some other types of alkaloids have been previously described as strong cyclooxygenase inhibitors. Therefore, it is necessary to further explore this group of secondary metabolites.

Keywords

alkaloid - cyclooxygenase - inhibitor

Acknowledgements

References

This work was supported by IGA VFU grant no. 54/2014/FaF.

1. Bekhit AA, Ashour HMA, Ghany YSA, Bekhit AEDA, Baraka A. Synthesis and biological evaluation of some thiazolyl and thiadiazolyl derivatives of $1 \mathrm{H}$-pyrazole as anti-inflammatory antimicrobial agents, European Journal of Medicinal Chemistry, 2008; 43(3): 456-463.

2. Ramprasath, VR, Shanthi P, Sachdanandam P. Anti-inflammatory effect of semecarpus anacardium Linn. nut extract in acute and chronic inflammatory conditions. Biological and Pharmaceutical Bulletin, 2004; 27(12): 2028-2031.

3. Sharma, PK, Kumar S, Kaushink P, ,Kaushink D, Dhingra Y, Aneja KR. Synthesis and biological evaluation of some pyrazolylpyrazolines as anti-inflammatory-antimicrobial agents. European Journal of Medicinal Chemistry, 2010; 45(6): 2650-2655.
\end{abstract}




\title{
THE MORPHOLOGICAL CHARACTERISTIC OF RAMSON (ALLIUM URSINUM L.)
}

\author{
Hrúzová M. ', Brindza J. ${ }^{2}$, Schubertova Z. ${ }^{3}$, Hajdu Š. ${ }^{2}$, Mňahončáková E. ${ }^{1}$ \\ ${ }^{1}$ Slovak University of Agriculture in Nitra, Botanical garden SUA in Nitra, Slovakia \\ ${ }^{2}$ Slovak University of Agriculture in Nitra, Faculty of Agrobiology and Food Resources, \\ Department of Genetics and Plant Breeding (IOBBB), Slovakia \\ ${ }^{3}$ Slovak University of Agriculture in Nitra, Institute of Biodiversity Conservation and Biosafety, Slovakia
}

\begin{abstract}
Aim Public interest about using of ramson (Allium ursinum L.) for food and phytopharmacology has increased in last few years. That is the reason why this species is an object of our experiments. The main target was determination of basic plants morphology.

Material/Methods In the experiment, we focussed on determination of basic morphological characters on the plant in fresh condition. The morphological features are: plant weight $(\mathrm{g})$, leaf weight $(\mathrm{g})$, root weight $(\mathrm{g})$, plant length $(\mathrm{mm})$, root length $(\mathrm{mm})$, leaf-stalk length $(\mathrm{mm})$ and leaf blade length $(\mathrm{mm})$. We have used 20 plants from locality Nová Ves nad Žitavou for our study.

Results: Based on the morphological analysis, we have assessed these attributes: plant weight is in the range 3.46$11.52 \mathrm{~g}$, leaf weight is in the range $2.23-7.06 \mathrm{~g}$, root weight is in the range 1.23-4.45 g, plant length is in the range $364.00-590.00 \mathrm{~mm}$, root length is in the range $80.00-210.00 \mathrm{~mm}$, leaf-stalk length is in the range $130.00-205.00 \mathrm{~mm}$ and leaf blade length is in the range $120.00-220.00 \mathrm{~mm}$. We have determined high index of variability (32.9-39.6\%) for all weight attributes and middle index of variability (14.22-15.33\%) for length attributes.

Conclusions Our achievements documented that on this location is big variability of morphological characters on plants, which we can use in search stage. Due to public interest in ramson (A. ursinum L.), we will try to secure selection of plants to get the new types. These new types can be used for cultivation in home gardens. With this solution, we can reduce over-harvesting in nature, especially in national parks.
\end{abstract}

Keywords Allium ursinum-morphology-plants - leaf-root

Acknowledgements The paper was worked within the international network AGROBIONET with grant of European Community, within project: Building of research centre 'AgroBioTech', project no. 26220220180. 


\title{
INHIBITION OF ASPERGILLUS NIGER BY USING THE VOLATILES FROM PLANTS ENCAPSULATED INTO MESOPOROUS SILICA MATERIAL MCM-41
}

\author{
Janatová A. ${ }^{\prime}$, Klouček P. ${ }^{2}$, Bernardos A. ${ }^{1,3}$ \\ ${ }^{1}$ Department of Crop Production, Faculty of Agrobiology, Food and Natural Resources, \\ Czech University of Life Sciences Prague, Czech Republic. \\ ${ }^{2}$ Department of Quality of Agricultural Products, Faculty of Agrobiology, Food and Natural Resources, \\ Czech University of Life Sciences Prague, Czech Republic. \\ ${ }^{3}$ Universitat Politècnica de València, Centro de Reconocimiento Molecular \\ y Desarrollo Tecnológico (IDM), Valencia, Spain.
}

Abstract

Keywords

References
Aim The main objective of this work is to determine and compare the antifungal activity of seven volatile compounds from plants encapsulated in mesoporous silica material MCM-41 with the same ingredients in a clean condition. Another objective is to follow the course of evaporation of seven encapsulated substances and the same substance in a pure state, and the results compared with the time course of antifungal activity.

Material/Methods The subject of testing was the fungicidal activity of seven volatile compounds from plants with claimed fungicidal activity - thymol, carvacrol, thymoquinone, eugenol, cinnamaldehyde, diallyl disulfide and allyl isothiocyanate. Testing was performed in vitro by modified agar diffusion method. To provide longer-term effects by controlled release and ease of application, these substances were encapsulated into mesoporous silica MCM- 41 material with a pore size of 2-3 $\mathrm{nm}$ and compared with the effects of substances in pure condition.

Results Fungicidal activity was verified in five out of the seven tested substances. Carvacrol in minimal inhibitory dosage (MID) of $0.5 \mathrm{mg}$ or less and cinnamaldehyde in MID of $1 \mathrm{mg}$ have shown the highest fungicidal activity, but there was no significant difference in the results between the encapsulated version and the pure variation. Thymol, carvacrol and tymochinon have appeared to be much more effective against Aspergillus niger in the encapsulated state. When evaluating after 14 days, it was necessary to implicate an eight times larger dosage of thymol in a clean condition $(4 \mathrm{mg})$ compared to just the encapsulated thymol $(0.5 \mathrm{mg})$, two times larger dose of eugenol in a clean condition (4 mg) compared to just half of encapsulated eugenol $(2 \mathrm{mg})$ and thymoquinone in a clean condition did not work at all, while the dose necessary for complete inhibition was $1 \mathrm{mg}$ of encapsulated thymoquinone. Diallyl disulphide and allyl isothiocyanate appeared to be almost ineffective against $A$. niger and in testing the evaporation rate, the clean state of both had completely evaporated within 24 hours.

Conclusions It has been proven that by the encapsulation of selected volatiles, excluding sulfur compounds, their long-term effectiveness is ensured by controlled release and easy handling, including application without affecting their fungicidal activity. This technology could have a significant impact, especially in medicine, the food industry and agriculture.

thymol - carvacrol - thymoquinone - eugenol - cinnamaldehyde - diallyl disulphide - allyl isothiocyanate - Aspergillus niger $-M C M-41$

1. Bakkali F, Averbeck S, Averbeck D, Idaomar M. Biological effects of essential oils - A rewiew. Food and Chemical Toxicology 2008; 46:446-475.

2. Bernardos A, Aznar E, Coll C, Martinez-Manez R, Barat JM, Marcos MD, Sancenon F, Benito A, Soto J. Controlled release of vitamin $B_{2}$ using mesoporous materials functionalized with amine-bearing gate-like scaffoldings. Journal of Controlled Release 2008; 131:181-189

3. Kloucek P, Smid J, Frankova A, Kokoska L, Valterova I, Pavela R. Fast screening method for assessment of antimicrobial activity of essential oils in vapor phase. Food Research International, 2012; 47, 2: 161-165. ISSN: 0963-9969.-9969. 


\title{
ANTIMICROBIAL EFFECT OF ACTIVE SUBSTANCES IN SELECTED MEDICINAL PLANT SPECIES
}

\author{
Kalhotka L. ', Pluháčková H. ', Kocourková B. ', Jaglič Z. ', Vrtková I. ',Lojková L.
}

${ }^{1}$ Mendel University in Brno, Faculty of Agronomy, Department of Medicinal Plant, Brno, Czech Republic

${ }^{2}$ Veterinary Research Institute, Brno, Czech Republic

Abstract

Keywords

Acknowledgements

References
Aim The aim of this research is to evaluate the antimicrobial effects of active substances in selected medicinal plant species.

Material/methods Selection of plant species based on already proven antibacterial effects of plant secondary metabolites on microbes that cause mastitis was performed at the Faculty of Agronomy, Mendel University in Brno, according to following criteria:

The species is used in pharmacy and food additives for containing anti-inflammatory active substances.

The species is economically accessible in the Czech Republic from cultivating areas as a medicinal plant intended for further processing.

The species is processed according to the GPP and in the mode of critical points system and Hazard Analysis and Critical Control Point (HACCP) according to the order No. 147/98 Sb.

Following species were selected: chamomile - Matricaria recutita, marigold - Calendula officinalis, sage - Salvia officinalis, St. John's Wort - Hypericum perforatum, caraway - Carum carvi, hops - Humulus lupulus and purple coneflower - Echinacea purpurea. Ethanol and propylenglycol extracts were obtained from selected species. Total bacterial count (CPM) was determined in the extracts, as well as bacterial count of the Enterobacteriaceae family, aerobic heat-resistant microorganisms, coagulation-positive staphylococcus (Staphylococcus aureus) and micromycetes (yeasts and molds). Results Only very small amounts of microbes or no microbes at all were found during continuous evaluation of microbiological purity. The most contaminated was marigold extract, in which the total bacterial count $100 \mathrm{KTJ} / \mathrm{ml}$ was determined. The presence of coagulation-positive staphylococcus was also found in this sample. Microbial contamination was present also in chamomile and sage extracts.

Conclusion Results of the plant extracts efficiency against mastitis causing pathogens showed that the extracts from chamomile, St. John's Wort, marigold and hops are efficient. Caraway was absolutely inefficient.

Matricaria recutita - Calendula officinalis - Salvia officinalis - Hypericum perforatum - Carum carvi - Humulus lupulus - Echinacea purpurea - extracts - antimicrobial - mastitis

This work was supported by the grant project NAZV QJ1210301'Research, new products and services for the creation of a Mastitis Prevention, Detection and Healing Support Center' from the National Agency for Agricultural Research (NAZV).

1. Schulze J, Schiemann M, Sonnenborn U. 120 Jahre E. coli - Bedeutung in Forschung und Medizin. Alfred-NissleGesellschaft e. V., Hagen, Deutschland, 2006. 55 p. ISBN 3-00-018600-X

2. Fernandes R. Microbiology Handbook Dairy Products. RSC Publ. and Leatherhead Food Int. Ltd.UK, 2009. 175 p. ISBN 978-1-905224-62-3

3. García S, Heredia N. Foodborne pathogens and toxins: an overview. In: Heredia N, Wesley I, García S: Microbiologically safe foods. Willey Hoboken New Jersey USA, 2009. 667 p. ISBN 978-0-470-05333-1

4. Jičínská E, Havlová J. Patogenní mikroorganismy v mléce a mléčných výrobcích. ÚZPI Praha, 1995. 106 p. ISBN 8085120-47-X

5. Ertrubk O, Ozbucak TB, Bayrak A. Antimicrobial activities of some medicinal essential olls. Herba Polonica, 2006; 52. $1 / 2: 58-66$ 


\section{KINETIC STUDY OF AMYLOID $\beta$ (42) AGGREGATION}

Abstract

Keywords

Acknowledgements

References
Kameníková M. ', Gažová Z. ${ }^{2}$, Nagy M. ${ }^{1}$

${ }^{1}$ Comenius University in Bratislava, Faculty of Pharmacy, Department of Pharmacognosy and Botany, Bratislava, Slovakia ${ }^{2}$ Slovak Academy of Science, Institute of Experimental Physics, Košice, Slovakia

Aim Nowadays, there are approximately 50 disorders, which are associated with the misfolding of normally soluble, functional peptides and proteins, and their subsequent conversion into aggregates, of which the examples are amyloid fibrils. Fibrils formation is often associated with loss of protein functionality and generation of toxic intermediates in the process of self-assembly. One of these peptides is amyloid $\beta$, which represents the main component of senile plaques.

Material/Methods Various protocols were tested in order to obtain different types of amyloid $\beta(42)$. The kinetic behaviour of the monomeric amyloid $\beta \otimes(42)$ aggregation was evaluated using Thioflavin T fluorescence method and confirmed by atomic force microscopy (AFM).

Results Different preparation techniques resulted in the formation of monomers, oligomers and fibrils of amyloid $\beta(42)$.

Conclusions Prepared aggregates will be further used in order to study their interactions with human serum albumin, and also concurrent combining with selected plant secondary metabolites.

amyloid $\beta$ (42) - Thioflavin T method - atomic force microscopy - aggregation - monomers - oligomers - fibrils

The research leading to these results has received funding from the grant UK/163/2015.

1. Cheng B. Inhibiting toxic aggregation of amyloidogenic proteins: A therapeutic strategy for protein misfolding diseases. Biochimicaet Biophysica Acta. 2013; 1830: 4860-4871.

2. Knowles TP, Vendruscolo M, Dobson CM. Theamyloid state and its association with protein misfolding diseases. Nature Reviews Molecular Cell Biology. 2014. 2014; 15: 384-396.

3. Yiannopoulou KG, Papageorgiou SG. Current and future treatments for Alzheimer's disease. Therapeutic Advances in Neurological Disorders. 2013; 6: 19-33. 


\title{
THE CONCENTRATION OF SELECTED PHENOLICS SUBSTANCES IN SOME SPECIES OF LAMIACEAE FAMILY
}

\author{
Kobida L.. ', Habánová M. ${ }^{2}$, Kobidová R. ${ }^{1}$, Luščáková D. ', Habán M. ${ }^{1}$ \\ ${ }^{1}$ Slovak University of Agriculture in Nitra, Faculty of Agrobiology and Food Resources, \\ Department of Sustainable Agriculture and Herbology, Slovakia \\ ${ }^{2}$ Slovak University of Agriculture in Nitra, Faculty of Agrobiology and Food Resources, \\ Department of Human nutrition, Slovakia
}

Abstract

Keywords

Acknowledgements

References
Aim Medicinal plants have served as rich sources of pharmacologically active substances. They contain antioxidant substances as polyphenolic acids (Newman, Crag, 2007). Phenolic compound are secondary metabolities that have been shown to impact human health (Steinmetz and Potter, 1996). The aim of this study is to assess the concentration of phenolic acids in five Lamiaceae species, Mentha piperita, Melissa officinalis, Lavandula angustifolia, Origanum vulgare and Salvia officinalis for their chemical composition.

Material/Methods Plants of five Lamiaceae species were field cultivated in Kolíňany and Nitra during 2 years. Phenolic acids were extracted from dry plants with methanol/water solution $(60 / 40, \mathrm{v} / \mathrm{v})$. Extraction procedure was described by Lin and Harnly, 2007. Extracts were analysed by WATERS BREEZE high-performance liquid chromatography, HPLC with dual UV-VIS detector and SYMMETRY $250 \times 4.6 \mathrm{~mm}$ column (WATERS).

Results On the basis of retention time and UV visible spectra compared with those of authentic standards, we analysed following phenolic acids: rutin, quercetine, rosmarinic acid and caffeic acid. Level of phenolic acids was expressed in mg.kg ${ }^{-1}$ and was: rutin - Mentha piperita (79.4-101.6), Melissa officinalis (27.4-214.5), Lavandula angustifolia (0-11.1), Origanum vulgare (not detected), Salvia officinalis (0-11.2), rosmarinic acid - Mentha piperita (4755.5-6658.7), Melissa officinalis (8178.55-9244.1), Lavandula angustifolia (4613.8-6895.2), Origanum vulgare (5899.6-8986.2), Salvia officinalis (6564.03-7099.6), quercetin was from 0.13 (Origanum vulgare) to $1.46 \mathrm{mg} \mathrm{kg}^{-1}$ (Lavandula angustifolia) and caffeic acid from 313.8 (Lavandula angustifolia) to $1103.2 \mathrm{mg}^{\mathrm{kg}} \mathrm{k}^{-1}$ (Salvia officinalis).

Conclusion In the present work, an HPLC method has been developed and applied for the identification and characterisation of active phenolic components in Lamiaceae species.The weather variables like rainfall, temperature, bright sunshine hours and evaporation at different growth phases had a definite bearing on the level of phenolic acids production.

Lamiaceae - phenolics acids - HPLC

The work was supported by VEGA project No. 1/0544/13 and VEGA project No. 1/0127/14.

1. Newman DJ, Cragg GM. Natural products as sources of new drugs over the last 25 years. Journal of Natural Products. 2007; 70: 461-477.

2. Steinmetz KA, Potter JD. Vegetables, fruit and cancer prevention: A review. J. Am. Diet. Assoc., 1996; 96: 1027-1039.

3. Lin LZ, Harnly JA. Screening Method for the Identification of Glycolysated Flavonoids and Other Phenolics Compound Using a Standard Analytical Approach for All Plant Materials. J. Agric. Food Chem. 2007; 8, 55: 1084-1096. 


\title{
IS PHOSPHOLIPASE A2 SIGNALING PATHWAY INVOLVED IN REGULATION OF ALKALOID BIOSYNTHESIS IN PAPAVERACEAE?
}

\author{
Kováčiková V. ', Kollárová R. ${ }^{1}$, Obložinský M. ${ }^{1}$, Heilmann M. ${ }^{2}$, Heilmann I. ${ }^{2}$
}

${ }^{1}$ Department of Cellular and Molecular Biology of Drugs, Faculty of Pharmacy, Comenius University in Bratislava, Slovakia ${ }^{2}$ Department of Cellular Biochemistry, Institut of Biochemistry and Biotechnology, Martin-Luther-University, Germany

Abstract

Keywords

Acknowledgements
Aim To study the connection between phospholipase $A_{2}\left(P L A_{2}\right)$ signalling cascade and alkaloid biosynthesis in Papaveraceae species under stress conditions.

Material/Methods The experiments were performed on opium poppy plants and California poppy's suspension cultures.

Opium poppy plants were growing hydroponically for 5 -weeks. For experiment, the plants were incubated for 24 hours in $50 \mu \mathrm{M}$ solution of PLA $\mathrm{A}_{2}$ inhibitor - aristolochic acid or soil solution with $0.1 \%$ dimethyl sulfoxide, DMSO (control), respectively. Then, leaves were mechanically wounded and incubated for 3 or 5 hours.

LC-MS analysis

Ground leaves were subjected to extraction by shaking with 50\% methanol. Separations were performed on Agilent 1290 Infinity high-performance liquid chromatography, HPLC. The analytes were detected on-line by ESI-MS/MS using an API 3200 triple-quadrupole LC-MS/MS system. Alkaloids (reticuline, salutaridine, thebaine, codeine, morphine) were quantified using dextromethorphan as internal standard.

California poppy's suspension cultures prepared from long-term callus cultures were maintained in the liquid medium according to Murashige and Skoog (1962). Methyljasmonate $(100 \mu \mathrm{M})$ was added into the suspension cultures on the $14^{\text {th }}$ day of subcultivation. Specific lipoxygenase (LOX) inhibitor phenidone was added into the culture 30 minutes before elicitation. The period of elicitor treatment was 48 hours.

Sanguinarine determination

Sanguinarine was extracted from $5 \mathrm{~g}$ of fresh mass and was identified by thin-layer chromatography (TLC) using the standard sample of sanguinarine under UV illumination at $366 \mathrm{~nm}$ (Reprostar II, Camag). The amounts of sanguinarine were determined using a Perkin-Elmer LS-30 luminiscence spectrophotometer at $324 \mathrm{~nm}$ of excitation and $408 \mathrm{~nm}$ of emission wavelengths.

Results In intact poppy plants, inhibition of PLA decreased level of thebaine and codeine, though morphine production was slightly increased. In control group, wounding significantly induced production of alkaloids. Three hours after wounding, higher level of alkaloids (except codeine) than in control plants in case of PLA inhibition was observed. Five hours after wounding, no difference in alkaloid content compared to the control group was observed. In California poppy in vitro cultures, methyljasmonate (MJ) significantly increased sanguinarine production. On the other hand, the pre-treatment of cultures with phenidone before elicitation had suppressed the sanguinarine production.

Conclusions Inhibition of PLA 2 or LOX, respectively, in Papaveraceae changed the common alkaloid accumulation under stress condition. Understanding of cellular mechanisms responsible for the production of alkaloids as their defence reaction is an important step towards the application of genetic engineering in poppy growing practices.

Papaveraceae - Alkaloids - Defence - Phospholipase A, Lipoxygenase

The realisation of the experiments was also supported by grants from the Faculty of Pharmacy Comenius University (FAF/31/2015) and by Slovak Grant Agency VEGA 1/0392/14, Bratislava, Slovakia. Special thanks to Dr. Jörg Ziegler for LC-MS analysis.

1. Murashige T, Skoog F. Revised medium for rapid growth and bioassay with tobacco tissue cultures. Physiol Plant 1962; 15: 473-497. 


\title{
MEDICINAL PLANTS AND DIABETIC VASCULOPATHY
}

\author{
Kuczmannová, A., Mučaji, P.
}

Comenius University in Bratislava, Faculty of Pharmacy, Department of Pharmacognosy and Botany, Slovak Republic

\section{Abstract}

Keywords

Acknowledgements

References
Aim Diabetes mellitus (DM) has alarmingly increasing incidence. According to WHO (World Health Organization) and IDF (International Diabetes Federation) reports, it is estimated that in the year 2030, DM will be the $7^{\text {th }}$ leading cause of death. The main symptom of DM is hyperglycaemia. Prolonged and uncontrolled hyperglycaemia leads to diabetic vascular complications - diabetic vasculopathy (DV). In general, there are six pathways of developing these complications. Oxidative stress, advanced glycation end products (AGE), polyol/aldose reductase pathway and protein kinase C (PKC) represent the main pathways. They result in cell and tissue damage and/or dysfunction by production of different transcription factors, pro-inflammatory cytokins and mediators, activation of pro-adhesive and prothrombotic properties and they can also enhance each other effects.

Material/Methods Nowadays, a lot of studies evaluate the possible antidiabetic and preventive effects of medicinal plants in DV. These different plant extracts have antioxidant, anti-inflammatory, hepatoprotective, choleretic and antibacterial effects, positively influence endothelial dysfunction and have little or no adverse effects. In our work, we studied antioxidant effects of Agrimonia eupatoria L. (AE) and Cynara cardunculus L. (CC) by different methods as well as the inhibition of a-glucosidase and advanced glycation end products (AGE) formation.

Results Agrimony water extract showed better antioxidant properties than artichoke. Both these medicinal plants inhibit the formation of AGE and agrimony is a good a-glucosidase inhibitor. Based on our results, we can conclude that agrimony and artichoke could be part of the adjunctive therapy of diabetes.

Conclusions Omar, E.A. et al describes in his article the best therapeutic option for DV would be an agent capable of directly regulating vascular homeostasis, thus preventing vascular injury and inflammation. For curing and preventing DV, there is search going on for a drug/agent that is an excellent antioxidant, could prevent AGE formation, inflammation, inhibition of PKC and aldose reductase.

diabetes mellitus - diabetic vasculopathy - antioxidants - Agrimonia eupatoria L. - Cynara cardunculus L.

This work was supported by grants no. FaF UK/15/2015 and VEGA-1/0646/14.

1. Mathers CD, Loncar D. Projections of global mortality and burden of disease from 2002 to 2030. PLoS Med. 2006; 3 : 442.

2. Omar EA et al. Herbal medicines and nutracueticals for diabetic vascular complications: Mechanism of action and bioactive phytochemicals. Current Pharmaceutical Design. 2010; 16: 3776-3807.

3. Hamik A, Atkins GB, Jain MK. Molecular mechanism of diabetic vasculopathy. Drug Discovery Today: Disease Mechanisms. 2005; 2: 11-17.

4. Orasanu G, Plutzky J, The pathologic continuum of diabetic vascular disease. Journal of the American College of Cardiology. 2009; 53(Supp. S): 35-42. 


\section{STUDY OF HORMETIC EFFECT OF NOVEL QUINOID- POLYPHENOL COMPOUND LIKE THE MODEL FOR POTENTIAL RESEARCH OF NATURAL HORMETICS}

Miláčková I.' , Račková L. ${ }^{2}$, Májeková M. ${ }^{2}$, Mrvová N. ${ }^{2}$, Štefek M. ${ }^{2}$

${ }^{1}$ Comenius University in Bratislava, Faculty of Pharmacy, Department of Pharmacognosy and Botany, Slovakia ${ }^{2}$ Slovak Academy of Sciences in Bratislava, Institute of Experimental Pharmacology and Toxicology, Slovakia

Abstract

Keywords

Acknowledgements

\begin{abstract}
Aim Many natural quinones and naphthoquinones possess a variety of beneficial pharmacological properties. In plants, the cytotoxic properties of quinones serve defensive roles against invading bacteria, fungi and parasites. In this regard, many quinones as well as polyphenols, exerting generally toxicity at high dosages, are able to induce favourable hormetic responses at a low dosage. Our aim is to investigate antioxidant or prooxidant properties of novel chloronaphthoquinone derivative of flavonoid quercetin (CHNQ) and its synthetic precursors quercetin and chlorohydroxynaphthoquinone (in short, 'quinone') in human neonatal B-HNF-3 fibroblasts. In addition, we studied the cytotoxic effects of the compounds as well as their potential paradoxic protection at low dose in oxidative stress. Material/Methods The compound CHNQ was synthesised by BEL/NOVAMANN (Bratislava). The experiments were provided on cell culture of human neonatal fibroblasts B-HNF-3. The apoptotic/necrotic changes were assessed by ethidium bromide and acridine orange (EB/AO) staining assay and by methods of flow cytometry as well as cytotoxicity was determined by MTT test and neutral red (NR) assay, all after 24 hours. Generation of intracellular oxidants was assessed using $\mathrm{H}_{2}$ DCF-DA and DHE probes with different specificity to reactive oxygen species, ROS.

Results The highest concentrations $(35 \mu \mathrm{M}, 100 \mu \mathrm{M})$ of CHNQ after 24 hours treatment caused cytotoxicity by increasing oxidative stress inside the cells that started apoptosis as well as necrosis. The lower concentration (10 $\mu \mathrm{M})$ of CHNQ caused increased protection of the cells against oxidative challenge via mild prevention of decline of activity of mitochondrial dehydrogenases and lysosomal injury.

Conclusions The new naphthoquinone derivative of CHNQ could be good example of hormetic as an electrofilic compound that causes in higher concentrations cytotoxicity, and paradoxically, in lower concentrations protects cells against oxidative stress. It acts probably thanks to activation of expression of protective enzymes via signal pathway Keap1-Nrf2-ARE. This study is applicable to next research of acting another natural hormetics with naphthoquinoid or polyphenol structure (plumbagin, juglone, lapachol, hesperidine, resveratrol...).
\end{abstract}

naphthoquinone - hormetics - cytotoxicity

The work was supported by grants VEGA 2/0031/12, VEGA 2/0067/11, by Agency of the Ministry of Education of the Slovak Republic for the Structural Funds of EU, Project ITMS 26240220040, Centre of Excellence for Glycomics, ITMS 26240120031, ITMS 26240220005, VEGA 1/0076/2013. 


\section{ANATOMICAL STRUCTURE OF THE ROOTS OF ECHINACEA ANGUSTIFOLIA DC VAR. ANGUSTIFOLIA AND ECHINACEA PALLIDA (NUTT.)NUTT.}

Mistríková l.

Comenius University in Bratislava, Faculty of Pharmacy, Department of Pharmacognosy and Botany, Slovak Republic

Abstract

Keywords

References
Aim Various species of Echinacea are often misidentified. There are many morphological similarities between the species, especially between $E$. angustifolia and E. pallida, and it has been shown that specimens are often confused in the medicinal plant market. E. angustifolia was classified as a variety of E. pallida (Bradley 1992). Since commercial roots of $E$. angustifolia have frequently been mixed with E. pallida, the study of anatomical characters of these species has become of great importance.

The aim of this study is an improvement of anatomical description of the root of E. angustifolia and E. pallida, because the structures of the cross sections of these roots are very similar.

Material/Methods The samples of plant material were obtained from the Medicinal Plants Garden. From samples, cross sections of the root were examined and compared.

\section{Results}

E. angustifolia

The secondary xylem is composed of narrow strands of vascular tissues separated by medullary rays. The secretory cavities are present in the cortex, in the secondary phloem and the secondary xylem. Sclereids with and without phytomelanin are found alone or in small groups. Within the secondary xylem, sclereids are arranged in small groups separated by parenchyma.

E. pallida

E. pallida has double the chromosome number as E. angustifolia, therefore, all studied structures (secretory cavities and sclereids) are larger on average on the cross sections of the root.

The structure of the xylem is very similar to E. angustifolia. The secretory cavities are often tangentially elongated. Sclereids are often coated with phytomelanin. They occur in the central cylinder and are solitary or in groups. Phytomelanin fills in the triangular intercellular spaces around the sclereids, making them appear star-shaped cross section.

Conclusions Anatomical investigations showed that for a precise identification of the roots, especially the sclerenchymatous structures (sclereids, sclerotic fibres), and the occurrence and distribution of phytomelan are of great importance. In addition, the specific arrangement of secretory canals and arrangement of the vessels in the cross sections can be used for the characterisation of these species.

Because of the highly similar anatomy of the studied species, Länger (2001) proposes that the microscopic proof of identity and purity of crude drugs of Echinacea must be done with un-comminuted material and the examination of cross sections.

Echinacea angustifolia, Echinacea pallida, root, anatomy

1. Bradley P. British Herbal Compendium: A Handbook of Scientific Information on Widely Used Plant Drugs, vol.1. Bournemouth: British Herbal Medicine Association1992.

2. Länger R. Anatomy of the underground parts of four Echinacea species and of Parthenium integrifolium. Scientica Pharmaceutica. 2001; 69:237-247. 


\section{ANTIOXIDANT CAPACITY AND NUTRACEUTICAL PROPERTIES AS PARAMETERS IN THE QUALITY EVALUATION OF SWEET BASIL (OCIMUM BASILICUM L.)}

Muráriková A., Neugebauerová J.

Mendel University in Brno, Faculty of Horticulture, Department of Vegetable Growing and Floriculture, Czech Republi

Abstract

Keywords

Acknowledgements

References

\begin{abstract}
Aim Sweet basil is one of the oldest herbs known to mankind (Suppakul et al., 2003). Its quality is determined, among other things, by sensoric properties. Antioxidant compounds play in diet an important role, as a health protecting factor (Alezandro et al., 2011). The objectives of this study are to evaluate ascorbic acid, crude fibre, total phenolic content and antioxidant capacities in popular varieties of sweet basil (Ocimum basilicum L.) grown in greenhouse. We have paid attention herein to the fact that content ascorbic acid, crude fibre, phenolic content and antioxidant capacity are important parameters in the quality evaluation of basil and this influences sensory properties.

Material/Methods Seven varieties ('Ohře,',Lettuce Leaf', 'Purple Opal','Dark Green', 'Mammollo Genovese,' 'Mánes' and 'Red Rubin') were grown in greenhouse of Faculty of Horticulture, Mendel University in Brno. The content of ascorbic acid was measured by high-performance liquid chromatography, HPLC. Crude fibre was determined in samples by fibre bag method. The aerial part of the plants were extracted by using methanol and evaluated for their antioxidant activity using DPPH (2,2-diphenyl-1 picrylhydrazyl) and FRAP (ferric reducing antioxidant power) methods. In addition, total phenolic content was determined by Folin-Ciocalteu reagent.

Results The ascorbic acid contents of sweet basil ranged from 87.0 to $181.94 \mathrm{mg} . \mathrm{kg}^{-1}$ fresh mass. The content of crude fibre varied between 15.72 and $18.41 \%$. We obtained different results in the evaluation of antioxidant capacity. Values obtained by using DPPH method between 14.55 and $25.28 \mathrm{mM} \mathrm{TE} .100 \mathrm{~g} \mathrm{~g}^{-1}$ dry weight, while obtained by using FRAP method between 36.29 and $68.26 \mathrm{mM} \mathrm{TE} .100 \mathrm{~g}^{-1}$ dry weight. The total phenolic content was determined from 3293.83 to $6158.29 \mathrm{mg} \mathrm{GAE} .100 \mathrm{~g} \mathrm{~g}^{-1}$ dry weight.

Conclusions The results suggest that chemicals such as vitamin $C$ and phenolic compounds are the contributors to the antioxidant activity in sweet basil. It is also rich in nutritive constituent as crude fibre. Therefore, basil can be used as a source of natural antioxidant and can be implemented through a balanced diet that could be much safer and cheaper than commercially available antioxidants.
\end{abstract}

ascorbic acid - antioxidants - crude fibre - phenolic compounds - pot plants - sweet basil (Ocimum basilicum L.)

The research was supported by the grant IGA No. 6/2015/591

1. Alezandro MR, Lui MCY, Lajalo FM, Genovese MI. Commercial spices and industrial ingredients: evaluation of antioxidant capacity and flavonoids content for functional foods development. Ciência e Tecnologia de Alimentos. 2011; 31 (2): 527-533, ISSN 0101-2061.

2. Suppakul P, Miltz J, Sonneveld K, Bigger SW. Antimicrobial properties of basil and its possible application in food packaging. J. Agric. Food Chem., 2003; 51 (11): 3197-3207. 


\title{
SYNERGY BETWEEN NATURAL COMPOUNDS AND ANTIBIOTICS AS A NOVEL STRATEGY FOR MRSA ERADICATION
}

\author{
Navrátilová A. ${ }^{1}$ Vančatová I. ${ }^{1}$ Čížek A., ${ }^{2,4}$ Žemličková H., ${ }^{3}$ Šmejkal K. ${ }^{1}$ \\ ${ }^{1}$ Faculty of Pharmacy, University of Veterinary and Pharmaceutical Sciences \\ Department of Natural Drugs, Brno, Czech Republic \\ ${ }^{2}$ University of Veterinary and Pharmaceutical Sciences Brno, \\ Department of Infectious Diseases and Microbiology, Czech Republic \\ ${ }^{3}$ National Institute of Public Health, National Reference Laboratory for Antibiotics, Czech Republic \\ ${ }^{4}$ University of Veterinary and Pharmaceutical Sciences Brno,CEITEC VFU, Czech Republic
}

\begin{abstract}
Aim: Serious infections have become a major problem of the population. They are caused, especially by bacteria insensitive to antibiotics. Bacteria have discovered resistance to all antibiotics; multi-drug-resistant (MDR) strains have grown. The most important MDR bacteria include methicillin-resistant Staphylococcus aureus (MRSA). MRSA is the most common and dangerous pathogen in all geographic regions (Alanis, 2005). It is a type of bacteria having more mechanisms of resistance and due to the presence of mec gene, it is immune to several types of antibiotics (penicillins, macrolides, aminoglycosides and fluoroquinolones); it is known as 'superbug' (Bassetti et al., 2009). Presented facts contribute to the urgent research of novel infection-fighting strategies. Some possibility for eradication of MRSA could come from natural sources. Especially a group of flavonoids and isoflavonoids substituted with geranyl and/or prenyl is considered as antimicrobial efficient 'Phytoanticipins' (Barron and Ibrahim, 1996). Our study is focussed on searching for new anti-infective constituents. We decided to confirm the hypothesis that antibacterially active mimulone (1) and 3'-O-methyldiplacol (2) obtained from Paulownia tomentosa show synergistic effects when combined with oxacillin (OXA), tetracycline (TTC), or ciprofloxacin (CIP). A case of potent synergy of epigallocatechin-3-gallate, EGCG with OXA and one with TTC were also shown for contrast.

MaterialS/Methods: We tested the effects of two-component combinations in vitro against twelve different strains of staphylococcus, including 10 clinical isolates of MRSA. MICs (minimal inhibitory concentration) and MBCs (minimum bactericidal concentration) were established using the broth microdilution method, the potential synergy was measured by the chequerboard titration technique and the sums of the fractional inhibitory concentrations $(\Sigma F I C s)$ were computed.

Results: In six cases, the results showed synergistic effects ( $\Sigma F I C$ 0.266-0.5) of the selected flavonoids when combined with oxacillin. In another eight cases, some effect was observed, and the values obtained did not differ greatly from synergy ( $\Sigma$ FIC 0.508-0.625). The effect of combining flavonoids with tetracycline was found to be only additive ( $\Sigma$ FIC $0.563-1$ ) in all cases. No significant synergy was found for combinations of flavonoids with ciprofloxacin. Synergistic effects were also found for the combination of EGCG with tetracycline ( $\Sigma$ FIC 0.375 ) or oxacillin ( $\Sigma$ FIC 0.5$)$. All of the other results for the application of EGCG against strains of MRSA showed only additivity (EFIC 0.531-1).
\end{abstract}

Keywords 3'-O-methyldiplacol-mimulone-MRSA-Paulownia tomentosa-synergy

Acknowledgements The financial support of this work by the IGA UVPS Brno (grant No. 93/2012/FaF to Alice Navrátilová) is gratefully acknowledged.

References 1. Alanis AJ. Resistance to antibiotics: Are we in the Post Antibiotic Era? Arch. Med. Res. 2005; 36: 697-705.

2. Barron D. Ibrahim, R.K., Isoprenylated Flavonoids - A Survey. Phytochemistry. 1996; 43: 921-982.

3. Bassetti M, Nicco E, Mikulska M. Why is community-associated MRSA spreanding across the world and how will it changed clinical practice? Int. J. Antimicrob. 2009. Ag. 34: S15-S19. 


\title{
EVALUATION OF GLYCYRRHIZIN CONTENT IN GENETIC RESOURCES OF LIQUORICE (GLYCYRRHIZA L.) TAXA IN THE CZECH REPUBLIC
}

\author{
Neugebauerová J.
}

\section{Abstract}

Keywords

Acknowledgements

References
Aim Liquorice (Glycyrrhiza L., Fabaceae) species are perennial herbs native to the Mediterranean region, Central to Southern Russia and Asia Minor to Iran, now widely cultivated through Europe, Middle East and Asia. Genetic resources of liquorice were integrated into the collection in the experimental fields of Mendel University in Brno, Faculty of Horticulture in Lednice in the years 1995-2014. The genus Glycyrrhiza L. consists of about 30 species (Nomura et al., 2002). The Glycyrrhiza L. genus was subdivided into two parts (Kruganova, 1955) representing true (Euglycyrrhiza Bois.) and pseudo (Pseudoglycyrrhiza Regel. Krug.) licorice species. Euglycyrrhiza group (G. glabra, G. uralensis, G. inflata, G. korshinskyi, G. aspera) produce glycyrrhizin and the others, G. echinata, G. macedonica, G. lepidota and G. pallidiflora, in group Pseudoglycyrrhiza Regel. Krug. produce macedonoside C as a major saponin (Kruganova,1955; Hosonoet et al., 2000).Roots and rhizomes are frequently used in food technology and pharmacy. Czech Pharmacopoeia mentions Liquiritiae radix as unpeeledor peeled, whole or cut root and stolons of species Glycyrrhiza glabra L. and/or Glycyrrhiza inflate Bat. and/or Glycyrrhiza uralensis Fisch. Roots and stolons must contain at least $4.0 \%$ of glycyrrhizic acid $\left(\mathrm{C}_{42} \mathrm{H}_{62} \mathrm{O}_{16}\right)$ counted on the dried drug.

MateriaL/ MethodS The glycyrrhizin of Glycyrrhiza L. taxa was measured by the high performance liquid chromatography (HPLC) according to the Czech Pharmacopoeia 2009 (Liqiuriteae radix).

Analyses were performed by RP-HPLC in a LCO-101 analytical column. The content of glycyrrhizin was expressed in percentage. The results were recalculated on the dried drug.

Results The content of glycyrrhizic acid ranged between 1.07-13.38\%. The lowest content (1.07\%) was determined in G. pallidiflora Maxim. The highest content of glycyrrhizic acid (13.38\%) among all analysed taxa was G. glabra L. Conclusions Content compounds of Glycyrrhiza L are mainly influenced by plant species and genotype.

\section{genetic resources - Glycyrrhiza L. - glycyrrhizic acid - HPLC - Czech Republic}

The results were obtained with financial support from the Ministry of Agriculture under the 'National program for conservation and utilization of genetic resources of plants, animals and micro-organisms'

1. Nomura T, Fukai T, Akiyama T. Chemistry of phenolic compounds of licorice (Glycyrrhiza species) and their estrogenic and cytotoxic activities. Pure and Applied Chemistry. 2002; 74: 1199-1206.

2. Kruganova EA. Обзорвидов Glycyrrhiza L. и Meristotropis Fish. EtMey. Тр.Ботан. ин-та АНСССР. 1955; Сер. 1. Вып. 2: 161-197

3. Hayashi H. et al. Phylogenetic relationship of six Glycyrrhiza species based on rbcL sequences and chemical constituents. Biol Pharm Bull. 2000; 23(5):602-6

4. Český lékopis. 2. díl Grada Publishing. 2009; Praha, ISBN 978-80-247-2994-7 


\title{
ENVIRONMENTALLY FRIENDLY STRATEGY FOR MEDICINAL PLANTS PROTECTION AGAINST STRESS?
}

\author{
Ohlsson A.B. ${ }^{1}$, Kozáková A. ${ }^{2}$, Lindström A. ${ }^{3}$, Pobořilová Z. ${ }^{4}$,Berglund T. ${ }^{1}$ \\ ${ }^{1}$ School of Biotechnology, KTH Royal Institute of Technology, Stockholm, Sweden \\ ${ }^{2}$ The Czech Academy of Sciences, Institute of Microbiology, v. v. i.. Prague, Czech Republic \\ ${ }^{3}$ Dalarna University, School of Technology and Business Studies, Falun, Sweden \\ ${ }^{4}$ University of Veterinary and Pharmaceutical Sciences, Faculty of Pharmacy, \\ Department of Natural Drugs, Brno, Czech Republic
}

\section{Abstract}

Keywords

References
Aim Plants in greenhouses are seldom exposed to UV-B radiation, which is a natural part of the solar spectrum. When seedlings are moved outdoors, they often react with stress responses, partly due to UV-B exposure. UV-B can give a broad stress response and increased resistance to stress, for example, pathogens and herbivors. UV-B exposure already in the greenhouse may prepare and strengthen the plants for outdoor conditions as well as other stress factors.

Material/Methods Scots pine (Pinus sylvestris L.) needles were analysed regarding content of thiobarbituric acid reactive substances (TBARS) as a measure of lipid peroxidation (Zhang et al., 2007), total phenolic substances (Swain and Hillis, 1959) and dehydrin gene expression (Wachowiak et al., 2009).

Results Stress response in pine seedlings moved outdoors 2 months after sowing was compared with control seedlings left in the greenhouse and seedlings moved outdoors but covered by a protecting cloth. Unprotected outdoors seedlings showed increased levels of TBARS and phenolic substances, while seedlings beneath the cover were unchanged. Changed expression of defense-related genes is a common response to stress. One dehydrin gene in pine (PsDhn5) was downregulated in the unprotected outdoors seedlings.

Conclusions The effects on oxidative stress (TBARS) and defense (phenolic substances) is in line with visible stressrelated symptoms on conifer seedlings when moved outdoors, and could therefore be a tool in the development of a new protecting strategy. Downregulation of PsDhn5 fits well with our results that this gene is also downregulated by drought stress. Epigenetic mechanisms play important roles in plant defense induction (Bräutigam et al., 2013). We have previously shown epigenetic effects of UV-B exposure of spruce seedlings, and a concomitant increase in volatile terpenoids emitted, known to have effects on pine weevil behaviour (Ohlsson, et al., 2013). We aim at using this strategy for an environmentally friendly way to strengthen and protect medicinal plants against different kinds of attackers and other stress.

scots pine - epigenetic mechanisms - TBARS - dehydrin gene expression

1. Zhang F-Q,Wang Y-S, Lou Z-P, Dong J-D. Effect of heavy metal stress on antioxidative enzymes and lipid peroxidation in leaves and roots of two mangrove plant seedlings (Kandelia candel and Bruguiera gymnorrhiza) Chemosphere 2007; 67:44-50.

2. Swain T, Hillis WE. The phenolic constituents of Prunus domestica. I. - The quantitative analysis of phenolic constituents J. Sci. Food Agric. 1959; 10:63-68.

3. Wachowiak W, et al. Search for nucleotide diversity patterns of local adaptation in dehydrins and other cold-related candidate genes in Scots pine (Pinus sylvestris L.) Tree Genetics \& Genomes 2009; 5:117-132.

4. Bräutigam K, et al. Epigenetic regulation of adaptive responses of forest tree species to the environment Ecol. Evol. 2013; 3:399-415.

5. Ohlsson AB, Segerfeldt P, Lindström A, Borg-Karlson A-K. Berglund T. (UV-B Exposure of Indoor-Grown Picea abies Seedlings Causes an Epigenetic Effect and Selective Emission of Terpenes. Z. Naturforsch. 2013; 68:139 - 147. 


\section{TAXIFOLIN IN A ROLE OF INHIBITOR OF RAT 12/15-LIPOXYGENASE}

Pekárová M. ${ }^{1,2}$, Kuhn H. ${ }^{2}$, Obložinský M. ${ }^{,}$, Kollárová R. ${ }^{1}$, Bezáková L. ${ }^{1}$

${ }^{1}$ Comenius University in Bratislava, Faculty of Pharmacy Department of Cell and Molecular Biology of Drugs, Slovakia ${ }^{2}$ University Medicine Berlin - Charite, Institute of Biochemistry, Chariteplatz 1, D-10117 Berlin, Germany

\section{Abstract}

Keywords

Acknowledgements

References
Aim: Taxifolin (dihydroquercetin) is a flavonoid commonly found in Pseudotsuga taxifolia, Dahurian larch, syn Larix dahurica Turoz (Pinaceae) (Ivanov et al., 2011). Its antioxidant ability is superior to that of ordinary flavonoids compounds owing to its special structure (Zu et al., 2014). The antioxidant capacity of flavonoids and other polyphenols appears to be, in large part, due to their capability of scavenging reactive oxygen and nitrogen species (Weidman, 2014). In our study, we observed an antioxidant activity of taxifolin towards the rat 12/15-lipoxygenase (LOX). LOX belongs to a family of lipid peroxidising enzymes, which have been implicated in the pathogenesis of inflammatory and hyperproliferative diseases. The interaction of flavonoids with mammalian leukocyte lipoxygenase merits particular attention, since this enzyme is a potential target for the health-preserving effect of flavonoids (Ma et al., 2012).

Material/Methods: The inhibition activity of taxifolin was measured spectrophotometrically at the $\lambda 234 \mathrm{~nm}$. The decrease in enzymatic activity of rat 12/15-LOX was represented by lower formation of hydroperoxy fatty acids products of enzymatic reaction. The inhibition effect was observed at different concentrations of taxifolin (10-100$1000 \mu \mathrm{mol}^{. \mathrm{I}^{-1}}$ ) on two different model enzymes expressed in eukaryotic and prokaryotic expression systems.

Results: Taxifolin caused significant decrease of enzymatic activity of both type of enzymes. The highest inhibition of products formation was detected using $1000 \mu \mathrm{mol} . \mathrm{I}^{-1}$ concentration of taxifolin. Enzymes showed only less than $10 \%$ of their original activity. $I C_{50}$ - the half maximal inhibitory concentration of taxifolin was lower for LOX expressed in eucaryotic expression system, $22.9 \mu \mathrm{mol} . .^{-1}$. IC $\mathrm{C}_{50}$ of taxifolin for LOX expressed in procaryotic expression system was $27.5 \mu \mathrm{mol}^{-1} \mathrm{I}^{-1}$.

Conclusions: A prominent property of flavonoids is their antioxidant capacity that may afford protection against oxidative stress. Taxifolin in a role of an inhibitor showed its ability to decrease hydroperoxy fatty acid formation in an enzymatic reaction catalysed by LOX. IC $C_{50}$ of taxifolin defined using both types of $L O X$ in a role of peroxidising enzymes are corresponding with data found in literature (inhibition of mammalian 15-LOX).

Flavonoid taxifolin - lipoxygenase - inhibition

This work has been supported by Slovak Grant Agency VEGA 1/0885/13, Bratislava, Slovakia.

1. Ivanov I et al.. Tight association of N-terminal and catalytic subunits or rabbit 12/15-lipoxygenase is important for protein stability and catalytic activity. Biochimica et Biophysica Acta. 2011; 1811: 1001-1010.

2. Zu YUY, Wu W, Zhao X, Wang W, Zhong C, Zhaou X. Enhancement of solubility, antioxidant ability and bioavailability of taxifolin nanoparticles by liquid antisolvent precipitation technique. International Journal of Pharmaceutics, 2014; 471: 366-376.

3. Weidman A, Dihydroquercetin: More than just an impurity? Eur. J. Pharmacol 2014; 684: 19-26.

4. Ma C, Yang L, Wang W, Yang F, Zhao C, ZU Y. Extraction of dihydroquercetin from Larix gmelinii with ultrasoundassisted and micro-wave-assisted alternant digestion. J. Mol. Sci. 2012; 13: 8789-8804. 


\title{
NUTMEG AND MACE - EXOTIC SPECIES OF SPICES
}

\author{
Péterová N., Mňahončáková E.
}

Abstract

Keywords

References

\begin{abstract}
Aim The aim of the work is to compile a literary study focussed on the history, origin, culture, meaning and utilisation of exotic species of spices. The work specifies nutmeg, mace.

Material/Methods We focussed on the study of primary and secondary sources of information on the subject, mostly of foreign authors, to contribute by integrated data processing to expansion of knowledge and information on the cultivation, importance and utilisation in the world of highly desirable spices such as nutmeg and mace are.

Results Nutmeg and mace are part of the tree Myristica fragrans Houtt belonging to the family Myristicaceae. Taxonomically are placed among families Annonaceae and Lauraceae (Joseph, 1980). Nutmeg plant is a dioecious evergreen tree growing up to a height of approximately 15-20 m. Entire-edge leaves are leathery, alternate, ovate lanceolate, sharpened at the end. The leaf length is 4-12 cm and the width $2-7 \mathrm{~cm}$. The flowers are unisexual, the male plants are formed with bunchy inflorescences with four to eight flowers.

Nutmeg plant is round, about 3.5-5 cm big, greenish later khaki thin felt able berry. Nutmeg harvesting starts about 8 months after flowering. The highest quality crop is from the first harvest in April, the highest productivity is from the second harvest in July and the weakest and worst quality harvest is in November (Buckmire, 1992.) The main ingredients are nutmeg oil, starch, protein, pulp and minerals. (Gopalakrishnan, 1992). The taste and the effects are caused by releasing the essential oil. Al-betaines, et al., (2003) analysed the basic components of nutmeg and found out that nutmeg is a great source of potassium, magnesium and phosphorus. The oil content of the mace is between $20-35 \%$. In terms of myristicin content the higher concentration is in the East Indian nutmeg (13.5\%) (Lee, 2005). The main component of hydrocarbon monoterpenes are pinenes and sabinenes and the major flavouring components are Myristicin, safrole and elemicin, largely determining the taste and medicinal properties. Both oils are of qualitatively similar composition but with different content of components (Mallavarapu and Ramesh, 1998). Other studies have shown that the alcohol extract of nutmeg had antibacterial activity against enteropathogenic $E$. coli (Yokoigawa, 2002). Based on further experiments, it was discovered the mace has two antimicrobials. The first is malabaricone B [1- (2,6-dihydroxyphenyl) -9- (4-hydroxyphenyl) -1-nonanoate] and the other is C malabaricone [1- (2,6-dihydroxyphenyl) -9- (3,4- dihydroxyphenyl) nonane-1-one], and both show significant antimicrobial activity against various microorganisms, including Candida albicans and Staphylococcus aureus (Orabi, 1991).

Conclusions Nutmeg as the seed of the exotic tree is used as a spice supporting appetite and improving digestion. Nutmeg is an obscure spice, small nut or already milled powder, rarely used in our kitchen. Higher doses act as a hallucinogenic drug. Mace is not bloom but dried scrotum covering the seed - nutmeg. It has stronger flavour than nutmeg and is used mainly for preparation of soups.
\end{abstract}

spice - nutmeg - mace

1. Lee et al. Myristicin-induced neurotoxicity in human neuroblastom SK-N-SH cells. Toxicol. Lett. 2005; 157, 1:49-56.

2. Orabi KY, Mossa, JS, El-Feraly FS. Isolation and Characterization of Two Antimicrobial Agents from Mace (Myristica Fragrans). Journal of Natural, Products. 1991. 54(3): 856-859.

3. Mallavarapu GR, Ramesh S. Composition of essential oils of nutmeg and mace. Journal of Medicinal and Aromatic Plant Sciences. 1998; 20: 746-8.

4. Buskmire KU. Nutmeg production in Grenada;' Technical Bulletin 20, Caribbean Agricultural Research and Development Institute, University of the West Indies, St. Augustine, Trinidad. 1992.

5. Yokoigawa K. Antimicrobial activity of nutmeg against Escherichia coli 0157 J. Biosci. Bioeng. 2002.94 (4):315-320. 


\title{
ANTIMICROBIAL ACTIVITY OF COTINUS COGGYGRIA SCOP. LEAVES EXTRACTS
}

\author{
Rendeková K.' , Fialová S. ', Mučaji P.', Slobodníková L. ${ }^{2}$
}

${ }^{1}$ Comenius University in Bratislava,Faculty of Pharmacy, Department of Pharmacognosy and Botany, Slovakia ${ }^{2}$ Comenius University in Bratislava, Institute of Microbiology of the Medical Faculty and the Faculty Hospital, Slovakia

\section{Abstract}

Keywords

Acknowledgements

References
Aim Cotinus . coggygria Scop.(smoke tree), which belongs to a family Anacardiaceae, is wide spread from Southern Europe to Central China and the Himalayas (Novakovic, 2007). Growing resistance to antibiotic therapy in clinical use has made it necessary to examine new antimicrobial agents obtained from plants (Singh, 2010). C. coggygria Scop. has been used in traditional medicine for its antimicrobial and anti-inflammatory properties (Marcetić et al., 2013). Nowadays, we report a renewed interest about antibacterial properties of this medicinal plant. The aim of our study is to evaluate the antimicrobial activity of water and methanol extract of smoke tree (C. goggygria).

Methods The antimicrobial activity of leaves extracts on three different strains of Gram-positive bacteria and two strains of Gram-negative bacteria was tested. The sensitivity of bacteria was demonstrated by broth-microdilution method according to recommendation of EUCAST (European Committee on Antimicrobial Susceptibility Testing) (www.eucast.org). The antimicrobial activity was determined as the minimum inhibitory concentration (MIC) and minimum bactericidal concentration (MBC) of studied compounds. We examined antimicrobial activity of extracts prepared using water (CCW) and 60\% methanol (CC Met) as extracting solvents.

Results Water extract showed significant inhibitory effect against methicillin-resistant Staphylococcus aureus (MRSA) and methicillin-sensitive S. aureus (MSSA) strains and against Enterococcus faecalis, but no effect on Gram-negative bacteria. $60 \%$ methanol extract showed stronger inhibitory and bactericidal effect on Gram-positive bacteria than water extract, furthermore was effective on Gram-negative bacteria also. The results are shown in Table 1.

Table 1. Antibacterial activity of investigated extracts

\begin{tabular}{|c|c|c|c|c|c|}
\hline $\mathrm{c}\left[\mathrm{mg} \cdot \mathrm{ml}^{-1}\right]$ & $\begin{array}{l}\text { S. aureus CCM } \\
4750 \text { (MRSA) }\end{array}$ & $\begin{array}{l}\text { S. aureus CCM } \\
4223 \text { (MSSA) }\end{array}$ & $\begin{array}{l}\text { Escherichia coli } \\
\text { CCM } 3954\end{array}$ & $\begin{array}{l}\text { Pseudomonas } \\
\text { aeruginosa CCM } \\
3955\end{array}$ & $\begin{array}{l}\text { E. faecalis CCM } \\
4224\end{array}$ \\
\hline$C C W-\mathrm{MIC} / \mathrm{MBC}$ & $0.625 / 1.25$ & $0.625 / 1.25$ & $>80 />80$ & $>80 />80$ & $0.3125 / 2.5$ \\
\hline CCMet-MIC/MBC & $0.156 / 0.313$ & $0.156 / 0.313$ & $0.313 / 0.625$ & $0.156 / 0.625$ & $0.078 / 0.625$ \\
\hline
\end{tabular}

Conclusions Antibacterial activity of investigated extracts demonstrates the medicinal potential of these extracts in local antimicrobial therapy.

Cotinus coggygria Scop. the minimum inhibitory concentration (MIC), minimum bactericidal concentration (MBC), Gramnegative bacteria, Gram-positive bacteria

This study was supported by the grant of the Slovak Ministry of Education VEGA 1/0646/14 (Molecular aspects of protective effect of selected plant extracts on vascular impairment in experiments in vitro) and the grant FaF UK/6/2015 (Study of antimicrobial and antioxidant activities of selected plants extracts and their chemical analysis)

1. Novakovic M, VuCkovic I, Janackovic P, Sokovic M, Tesevic V, Milosavljevic S. Chemical composition, antibacterial and antifungal activity of the essential oils of Cotinus coggygria from Serbia. J Serb Chem Soc. 2007;72:1045-1051.

2. Marcetić M, Božić D, Milenković M, Malešević N, Radulovic S, Kovacevic D. Antimicrobial, antioxidant and anti. inlammatory activity of young shoots of the smoke tree, Cotinus coggygria Scop. Phytother. Res. 2013; 27:1658 1663.

3. www.eucast.org 


\title{
YIELDING AND QUALITY OF PLANTAIN (PLANTAGO MAJOR L.) RAW MATERIAL IN THE SECOND YEAR OF CULTIVATION
}

\begin{abstract}
of this plant contains a number of biologically active compounds with therapeutic properties (Samuelsen 2000). In Poland, the plantain raw material (leaves and herb) comes from natural sites. There are also studies connected to the cultivation of this plant (Andrzejewska-Golec, 2010) The aim of this study is to evaluate the effect of time of plantation establishment and raw material harvesting on the quality of plantain herb in the second year of cultivation.

Material/Methods Seeds to establish plantation were collected in 2011 on natural habitats located in Mazowieckie (Elsnerów), Lublin (Krzywda) and Podlasie (Antonowo) provinces. The seeds were sown in 2012 in early spring and in late spring. The raw material was harvested in 2013, when the plants were in vegetative phase and during their flowering. Directly after the harvest, the raw material was dried in a dryer chamber at $40^{\circ} \mathrm{C}$. Dry mass of herb per $1 \mathrm{~m}^{2}$ as well as content of iridoid glycosides, polyphenolic acids and tannins were determined.

Results Significantly higher mass of herb was obtained from plots where the seeds were sown in late spring compared to early spring sowing (respectively: $109.0 \mathrm{~g} \cdot \mathrm{m}^{2}$ and $91.0 \mathrm{~g} \cdot \mathrm{m}^{2}$ ). Plants collected in the flowering stage gave higher mass of herb than plants collected in the vegetative phase. Polyphenolic acid content ranged from 1.30 (province Lublin, late spring sowing, and second time of harvest) to $2.38 \%$ (province Lublin, early spring sowing second time of harvest). The highest content of iridoid glycosides from plots established in late spring was observed. Herb of population Antonowo (Podlasie province) contained significantly more of these compounds compared to the populations from Mazowieckie and Lublin province. Content of tannins ranged from 2.0 to $4.6 \%$.

Higher content of these compounds was observed in raw material harvested from plots where seeds were sown in late spring. Population Krzywda (Lubelskie province) was characterised by the highest content of these compounds. Conclusions The higher mass of herb is obtained when the plantations is establishing in late spring and when the harvest is carried out in the flowering stage of plants. That raw material is characterised also by the highest content of iridoid glycosides and tannins.
\end{abstract}

Abstract

Aim Plantain (Plantago major L.) is known and has been used by people for years. Present research shows that herb

Keywords

References
Plantain - cultivation - polyphenolic acids - iridoid glycosides - tannins

1. Andrzejewska-Golec E. Babka zwyczajna - pospolity chwast i roślina lecznicza. Panacea, 2010; 2 (31): 14-17.

2. Samuelsen AB. The traditional uses, chemical constituents and biological activities of Plantago major L. A review. J. Ethnopahrm. 2000; 71:1-21. 


\section{PLANT SUBSTANCES AS ACTIVE COMPOUNDS OF PACKAGING MATERIALS FOR FOOD}

Abstract

Keywords

Acknowledgements
Aim The evaluation of the antimicrobial and antioxidant activity of chosen plant substances incorporated in cover foil used for food packaging.

Material/Methods Antimicrobial activity of three concentrations of plant substances (mixture of essential oils, mixture of essential oil compounds) applied in special paint (Utility model No. 27586) on the packaging foil was tested on chosen types of food using Escherichia coli CCM 7929, Candida tropicalis CCM 8223 and Penicillium chrysogenum CCM 8034. Defined amount of cheese, sausage and vegetable was placed into the polystyrene bowls, inoculated by the cultures of the microorganisms mentioned above, covered by the active foils. The bowls were incubated in the refrigerator by $3-6^{\circ} \mathrm{C}$ for 24 hours, 48 hours. Last sampling was after 6 days of the incubation. In the term of the last measurement, the sensorial analyses was also performed. Antioxidant capacity of active foils covering the food was tested using the ORAC method (oxygen radical absorbance capacity) in multiwell-plates specially developed for this experiment.

Results Active foils showed the significant effect on the growth of the microorganisms. The most sensitive were moulds, $P$. chrysogenum, while $C$. tropicalis was the most resistant to the inhibition effect of the active foils. Bacteria like $E$. coli were significantly resistant. Some of the variants of the active foils showed high antioxidant properties at all types of food.

Conclusions The series of the experiments have confirmed the significantly high antimicrobial and antioxidants properties of a new type active foil with natural plant substances. On the base of the results, the most active substance for the special paint was chosen. This mixture will be encapsulated and incorporated in the special paint and will be used for the development of prototype of active foil for food industry.

antimicrobial - antioxidant - active foil - packaging - ORAC - plant substances

This work was supported by the project of TAČR - TA03010799 'The use of nanomaterials and natural extracts as functional materials in the development of active packaging materials with barrier effect, antimicrobial, protective and oxygen absorbing effect'.

1. Tajkarimi M. M., Ibrahim SA, Cliver DO. Antimicrobial herb and spice compounds in food: A review. Food Control, 2010; 21 (9): 1199-1218

2. Utility model No. 27586,2014

3. Pšeničková Z, Kalhotka L, Růžičková, G, SYNPO, a.s. Pardubice, Mendelova univerzita v Brně. Paint with antimicrobial property for the print onto the polymer foils, the food foils respectively. 27586, Industrial Property Office, Czech Republic. 


\title{
POTENTIAL THERAPEUTIC APLICATIONS OF PRENYLATED NATURAL SUBSTANCES
}

\section{Šmejkal K. ${ }^{1}$}

\author{
${ }^{1}$ University of Veterinary and Pharmaceutical Sciences Brno, Faculty of Pharmacy, \\ Department of Natural Drugs, Czech Republic \\ ${ }^{2}$ University of Veterinary and Pharmaceutical Sciences Brno, Faculty of Pharmacy, \\ Department of Molecular biology and Pharmaceutical Biotechnology, Czech Republic
}

Abstract

Keywords

Acknowledgements

References
Aim The flavonoids are a group of secondary metabolites biosynthetically derived from shikimic acid and polyketide pathways. They are plant pigments containing benzopyrane substituted with a phenyl ring at position 2 or 3 . Their aglycones can be lipophilic; their lipophilicity can be further enhanced by methylating the hydroxyl groups, or by prenylation or geranylation at different positions on the skeleton. The prenyl or geranyl moiety may be modified in different ways and enhances the interaction with organism.

Material/Methods Experimental in vitro and in vivo studies have revealed many biological and pharmacological activities of flavonoids. We worked with prenylated compounds from Morus alba and Paulownia tomentosa.

Results Inflammation is a multiple and complex response by the body to infection or injury. Prenylated compounds show pleiotropic effects and can modulate a broad spectrum of inflammatory regulatory nodes. Their anti-phlogistic action combines many particular effects: it can be mediated by several pathways: via anti-oxidant and pro-oxidant effects, by interacting directly with pro-inflammatory proteins, and by interacting with signal pathways and inhibiting the expression of inflammation-related genes. In vivo tests have confirmed all of the effects of flavonoids previously observed in in vitro experiments. The antibacterial effect of prenylated substances was confirmed, some synergy with standard antibiotics was observed against MRSA (methicillin-resistant Staphylococcus aureus).

Conclusions Prenylated phenols are good candidates for further research to discover new therapeutics for treatment of diseases connected with bacterial infection and inflammatory disorders.

phenol - separation - anti-inflammatory - antibacterial.

Thanks to all colleagues participating in this research.

1. Šmejkal et al. Antibacterial C-Geranylflavonoids from Paulownia tomentosa Fruits. Journal of Natural Products. 2008a; 71 (4): 706-709.

2. Navrátilová et al., Minor C-geranylated Flavanones from Paulownia tomentosa Fruits with MRSA Antibacterial Activity. Phytochemistry. 2013; 89: 104-113.

3. Hošek et al. Natural compound cudraflavone B shows promising anti-inflammatory properties in vitro. Journal of Natural Products. 2011; 74 (4): 614-619.

4. Hanáková Z, Hošk J, Babula J, Dall Acqua S, Václavík J, Šmejkal K. C-Geranylated Flavanones from Paulownia tomentosa Fruits as Potential Anti-inflammatory Compounds Acting via Inhibition of TNF-alpha Production. Journal of Natural Products. 2015; 78: 850-863.

5. Vochyanová Z. et al. Diplacone and mimulone ameliorate dextran sulfate sodium-induced colitis in rats. Fitoterapia. 2015; 101: 201-207. 


\title{
SALVIA OFFICINALIS L. CV.'KRAJOVÁ' - A SOURCE FOR THE HERBAL DRUG SALVIAE OFFICINALIS FOLIUM
}

\author{
Tekelová D., Tóth, J., Czigle, Sz., Grančai, D.
}

Comenius University in Bratislava, Faculty of Pharmacy Department of Pharmacognosy and Botany, Slovakia

\section{Abstract}

Keywords

Acknowledgements

References

\begin{abstract}
Aim Salvia officinalis L. (sage) is a common aromatic plant of the Lamiaceae family, widely cultivated for its medicinal and culinary purposes. Sage shows various biological activities and medicinal properties such as antioxidant, antiviral, antibacterial, antifungal, anti-inflammatory, antispasmodic, astringent and antihidrotic. The predominant medicinally valuable compounds are monoterpenes in essential oil ( $\alpha$ - and $\beta$-thujones, 1,8-cineol, camphor), diterpenes (carnosic acid, carnosol), triterpenes (ursolic and oleanolic acids) and phenolics - phenolic acids (rosmarinic acid) and flavonoids (luteoline and apigenine derivatives). The main antioxidative effect of $S$. officinalis was reported to relate to the presence of carnosic acid, carnosol, and hydroxycinnamic derivatives, especially rosmarinic acid.

This work deals with quality assessment of the herbal drug Salviae officinalis folium originating from the domestic cultivar 'Krajová' cultivated in Bratislava. For S. officinalis folium, the European Pharmacopoeia ( $8^{\text {th }}$ Edition) includes the essential oil quantification [1]. The content and composition of sage essential oil has been studied extensively in previous years. Changes of sage phenols content have not yet been studied well so far.

MaterialS/Methods Plant shoot harvest was carried out in the course of one vegetation year in the vegetative phenophase and flowering period. Secondary metabolites were quantified using pharmacopoeial methods. Total hydroxycinnamic derivatives (THD) content was quantified using spectrophotometric method according to the pharmacopoeial monograph Rosmarini folium (Arnow's reagent, $505 \mathrm{~nm}$ ) [1]. Rosmarinic acid was quantified by highperformance liquid chromatography, HPLC in a methanolic extract [2].

Results The THD content did not show significant changes in the course of 1 year (3-3.5\%), and maxima were observed in youngest plant shoot leaves and in newly grown shoots in September. Rosmarinic acid variability $(0.8-1.7 \%)$ showed the same trends.

Conclusions The THD and RA content in the studied cultivar 'Krajová' shows values corresponding to data in other references [3, 4]. Highest percentages of both THD and RA were found in top leaves, and values decreased in leaves from the lower part of the stem. A similar trend was observed when analysing essential oil content [5]. The content of THD and RA decreased at the flowering period. A similar decrease in the flowering phenophase was observed when studying essential oil content variations in sage leaves.
\end{abstract}

Salvia officinalis L. Cv. 'Krajová' - phenolic compounds - essential oil - plant organ - harvest time

This study was partially supported by a grant project of the VEGA agency, No. VEGA 2/0044/15.

1. European Pharmacopoeia $8^{\text {th }}$ Edition, Strasbourg: Council of Europe; $2014 ; 1369,4250$.

2. Tóth J, Mrlianová M, Tekel'ová D, Koreňová M. 2003. Rosmarinic acid - an important phenolic active compound of lemon balm (Melissa officinalis L.) Acta Fac Pharm Univ Comen, 2003; 50:139-146.

3. Lamaison JL, Pettitjean-Freytet C. Rosmarinic acid, total hydroxycinnamic derivates and antioxidant activity of Apiaceae, Boraginaceae and Lamiaceae medicinals. Ann Pharm Franc, 1990; 48:103-108.

4. Wang H, Provan GJ, Helliwell K. Determination of rosemaric acid and caffeic acid in aromatic herbs by HPLC. Food Chem 2004, 87:307-311.

5. Tekel'ová D, Felklová M. Salvia-officinalis L. cv Krajova.5. Contents of esential oil, ash and hydroxycinnamic acidderivatives in separate leaf insertions. Pharmazie, 1993. 48(12):938-940. 


\section{IS THE MILK THISTLE WEED IN SUSTAINABLE CROP ROTATION?}

Týr Š.

Slovak University of Agriculture in Nitra, Faculty of Agrobiology and Food Resources, Department of Sustainable Agriculture and Herbology, Slovak Republic

Abstract

Keywords

Acknowledgements

References
Aim Milk thistle - Silybum marianum (L.) Gaertn can be a winter annual (Martinelli et al., 2015) or a biennial medicinal plant (Alemardan et al., 2013, Haban et al., 2009). This study was focussed on milk thistle as a weed in the sustainable farming system with the crop rotation of maize and pea for grain, durum wheat and milk thistle.

Material/Methods The assessment of the occurrence of milk thistle in sustainable crop rotation was conducted at the Experimental Base of Faculty of Agrobiology and Food Resources, Slovak University of Agriculture in Nitra in the years 2012-2014.

Results An actual weed infestation of maize, pea and durum wheat stands with milk thistle was evaluated before preemergence application of herbicides in the spring time. Second screening of actual weed infestation of all stands in sustainable crop rotation with milk thistle was done before crops harvest. Screening of each field was made on $1-\mathrm{m}^{2}$ area with three replications. The three randomly established sample quadrants were situated minimally $10 \mathrm{~m}$ from field margin and apart from each other, respectively. The level of infestation was evaluated according to average density of weeds per square metre. Obtained data was statistically analysed by Statistica 7.0, Analysis of variance (ANOVA), Fishers Least Significant Difference, LSD test $(p=0.05)$. According to statistical analyses, in the year 2012 was the maize stands infested with the highest, statistically very significant amount of $S$. marianum (7.2 plants per $\mathrm{m}^{2}$ ). Stands of pea for grain in the second year after milk thistle cropping were infested in the years 2012-2014 only with 0.93 plants per $\mathrm{m}^{2}$. Durum wheat stands were not infested with milk thistle.

Conclusions The originality of this paper is in testing the introduction of a new prospective crops in sustainable crop rotation. Milk thistle does not infest fields within the reporting unit.

Silybum marianum L. Geartn. - weed infestation - sustainable crop rotation

The research presented in this paper was supported by the Project VEGA No 1/0513/12.

1. Alemardan A, Karkanis A. Salehi R. Breeding objectives and selection criteria for Milk Thistle (Silybum marianum L. Gaertn.) improvement. Not. Bot. Horti. Agrobo. 2013, Vol. 41, no. 2, pp. 340-347. ISSN 0255-965X

2. Haban M., Otepka P, Kobida L, Habánová M. Production and quality of milk thistle (Silybum marianum L. Gaertn) cultivated in cultural conditions of warm agri-climatic macroregion. In Hort. Sci. (Prague), 2009; 36, 2: 69-74. ISSN 1221-5279

3. Karkanis A, Bilalis D, Efthimiadou A. Cultivation of milk thistle (Silybum marianum L. Gaertn.), a medicinal weed. In Industrial Crops and Products, 2011; 34, 1: 825-830.

4. Nasiri Y, Feyzi P, Javanmard A. Effects of hydro and hormonal seed priming on seed germination of Milk Thistle under saline stress condition. Not. Sci. Biol. 2014. 6, 3: 374-380.

5. Martinelli T, Andrzejewska J, Salis M, Sulas L. Phenological growth stages of Silybum marianum according to the extended BBCH scale. In Annals of Applied Biology. 2015; 166, 1: 53-66. 


\title{
ELICITATION AS A TOOL TO IMPROVE PRODUCTION PROPERTIES OF MEDICAL PLANTS IN VITRO CULTURES
}

\author{
Urdová, J.', Balážová, A. ${ }^{2}$, Mučaji, P.'
}

${ }^{1}$ Comenius University in Bratislava, Faculty of Pharmacy Department of Pharmacognosy and Botany, Slovak Republic ${ }^{2}$ Comenuis University in Bratislava, Faculty of Pharmacy Department of Cellular and Molecular Biology of Drugs, Slovak Republic

\section{Abstract}

Keywords

Acknowledgements

References

\begin{abstract}
Aim The California poppy, Eschscholtzia californica, produces benzophenanthridine alkaloids (BPAs) such as the biologically active compounds, sanguinarine and chelerythrine. Sanguinarine and chelerythrine show activity against multiple targets associated with inflammation, cell cycle regulation, and apoptosis of cancer cells. In addition, sanguinarine was previously incorporated as an antiplaque agent in toothpastes and mouthwashes. Our recent study is focussed on investigation of influence of biotic (salicylic acid, methyl jasmonate) elicitors on production properties of E. californica suspension cultures.

Material/Methods In our experiment, we used suspension cultures of E. californica grown in Department of Cellular and Molecular Biology of Drugs in Bratislava. The cultures had been cultivated in Murashige and Skoog medium. For the elicitation, we used 14-day-old suspension cultures of 3rd subcultivation. Plant material was treated with different concentrations of methyl jasmonate and salicylic acid. Elicited suspension cultures were harvested after 24,48 and $72 \mathrm{~h}$ of elicitor treatment. The elicitation effect was evaluated on the basis of BPAs content in dose- and time-dependent manners. The experiments led to selection of the most effective elicitor and its concentration that is able to stimulate the production of secondary metabolites but, on the other hand, does not influence viability of cells.

Results The elicitors have been chosen based on the previous work of the Department of Cellular and Molecular Biology of Drugs in Bratislava. Methyljasmonate has stimulated production of sanguinarine in plant cultures of the family Papaveraceae. For the success of the experiment, it is vital that the concentration of elicitor and the duration of elicitation is just right. This work is highly experimental; therefore, the selection of the right concentration of elicitors can be very precarious.

Conclusions Concentration of elicitor is the factor that significantly affects the intensity of response of plant suspension cultures. Concentration of elicitor that is effective for one type of culture and works as stimulator can be, in other system, without response. This statement can also be applied for the time of exposition to elicitor. So, to find the right combination of concentration of elicitor and duration of elicitation for the specific plant cultures is always empirical.
\end{abstract}

Eschscholtzia californica - elicitation - benzophenanthridine alkaloids

This work was supported by grant no. UK/158/2014

1. Oldham JT, Hincapie M, Rejtar T, Kerr Wall P. Shotgun Analysis of yeast-elcitated California Poppy (Eschscholzia californica) suspensioun cultures producing enhanced levels of benzophenanthridine alkaloids. J. Proteome Res. 2010; 9:4337-4345.

2. Balažová $A$, Blanáriková V, Bilka F, Bilková A. Effect of combined biotic and abiotic elicitor on the sanguinarine formation in cell suspension cultures of Eschscholtzia californica Cham. Acta Facult Pharm Univ Comenianae. 2008; 55:58-63.

3. Namdeo A. Plant Cell Elicitation for Production of Secondary Metabolites. Pharmacogn. Rev. 2007;1:69-79. 


\section{OPTIONS OF HERBICIDES PROTECTION OF MILK THISTLE (SILYBUM MARIANUM (L.) GAERTN.)}

Vaculík A.

Agritec Plant Research Ltd., Department Plant Protections, Šumperk, Czech Republic

Abstract

Keywords

Acknowledgements
Aim Silybum marianum (L.) Gaertn. is sufficiently robust and competitive plant against most of weeds. But, especially in the early growth and development stages of growth can be significantly suppressed by quickly emerging annual monocots and broad-leaved weeds. At the same time, can be big problem perennial weeds and in our conditions, especially couch grass and thistle sown. Although in the past, there was performed also mechanical cultivation (hoeing), currently, in the case of occurrence of weeds, chosen is chemical protection, that is, using a suitable and registered herbicide. Currently, on S. marianum are permitted herbicides STOMP $330 \mathrm{E}$ with a.i. pendimethalin applied pre-emergently, then REFINE SX 50 with a.i. thifensulfuron-methyl, and Betanal maxxPro respectively Betanal Maxx Pro 209 OD with a.i. desmedipham, ethofumesate, phenmedipham and lenacil. These formulations are designed for post-emergence, respectively early post-emergence treatment. It is interesting that there is no registered graminicide for controlling annual and perennial monocots weeds, although our experiments showed that normal range of graminicides used in the Czech Republic is highly selective to $S$. marianum plants and even at dose rate controlling couch grass.

Material/Methods The trial in Silybum marianum with herbicides was conducted in years 2013-2015 on experimental fields on Šumperk locality. The trial was established, conducted and assessed according to the EPPO standards PP1 135 (3), 152 (3) and 181 (3). The application of herbicides was carried out post-emergently. The selectivity of used herbicides was evaluated by percentage scale in accordance with appropriate standard. The experimental plots were harvested and the yield of achenes per area unit was recorded.

Results The obtained results of observation of phytotoxicity of herbicides applied to Silybum plants showed that despite the slight phytotoxicity, it is recommendable post-emergence treatment with herbicide STOMP 400 SC Betanal MAXX PRO, REFIN 50 SX and Butisan STAR. No problems for phytotoxicity showed graminicidal products TARGA SUPER 5 EC, GARLAND FORTE and GALLANT SUPER, although they were used at higher doses against perennial monocotyledonous weeds. Interesting results brought products LONTREL 300 and BUTOXONE 400, which were contrary to attempt classified as herbicides liquidating volunteer seeds of milk thistle in succeeding crops. Their phytotoxicity was conversely very strong (up 95\%) and the surviving Silybum plants only vegetated, did not flower and thus, no seeds were created. Moreover, it is likely subsequent cereal crops phytotoxicity, respectively the efficiency would occur practically in $100 \%$. Yield assessment then only underscored and confirmed the phytotoxicity results observed on applied herbicides.

Conclusions The results obtained from a part of included herbicides demonstrated high selectivity to plants Silybum marianum and a positive effect of application on the yield of achenes per surface unit.

Silybum marianum - herbicides - selectivity - yield.

This contribution was prepared on the basis of results obtained from grant of Ministry of Agriculture Rozvoj organizace RO-0111. 


\section{QUALITATIVE PROPERTIES OF THE ESSENTIAL OIL FROM FLOWERHEADS OF THE SELECTEC CULTIVARS OF THE CHAMAEMELUM NOBILE (L.) ALL. SPECIES}

Vaverková Š. ', Habán M. ${ }^{1}$, Mikulášová M. ${ }^{2}$, Farkaš P. ${ }^{3}$

${ }^{1}$ Comenius University in Bratislava, Faculty of Pharmacy, Department of Pharmacognosy and Botany, Slovakia ${ }^{2}$ Comenius University in Bratislava, Faculty of Natural Sciences, Institute of Cell Biology and Biotechnology, Slovakia ${ }^{3}$ Slovak University of Technology in Bratislava, Faculty of Chemical and Food Technology, Slovakia

\section{Abstract}

Keywords

Acknowledgements

References
Aim Selected cultivars of Chamaemelum nobile (L.) All. (Asteraceae) are characterised by numerous biological effects, which are due, in particular to the activity of essential oils and flavonoids. The main objective was to find the most suitable planting conditions to produce essential oil of the best quality and to achieve the highest possible essential oil yields Balchin et al. (2004), Carnata et al. (2004), Omidbaigi et al. (2004).

Material/Methods The experiments were made on three different cultivars of Chamaemelum nobile - Flore Pleno, Discoidea and Doksan. The oil extraction was executed by an officinal method of the Slovak Pharmacopoeia SL 1 , namely the method for determination of essential oils without addition of decaline. The essential oil content was expressed in \% [ $\mathrm{v} / \mathrm{w}$ ], that is, calculated for $100 \mathrm{~g}$ of herbal material. Particular essential oil constituents were identified by comparison of their relative retention times and by comparison of the mass spectra of extracted constituents with the mass spectra of available standards and the mass spectra through the NBS 75K, Helwett Packard, INRA MASS and WILEY 275 (2001) databases.

Results We have extracted 54 constituents. Out of them, we have identified 32 major and minor components. A major component in all three cultivars was isobutyl-angelate, ranging between 33.6 and $37.4 \%$ and isoamyl-angelate between 18.8 and $20.5 \%$. Also, the representation of isobutyl-butyrate and methyl-isobutyrate was relatively high. In the essential oil from cv. Doxan, it reached the value of $8,2 \%$. This cultivar contained also a relatively high amount of L-pinene $-5.9 \%$, while the amount of mycene and pinocarvone ranged only between 1.7 and $2.8 \%$.

Conclusion Of the extracted 52 components, we have identified 34 constituents. Evaluated were percentual differences between the representation of such principal constituents like angelates and isobutyric acid derivatives in various cultivars. The highest content of isobutyl angelate was observed in the plants of cv. Doxan (37.4\%) and cv. Discoidea (35.0\%). The dominant constituents were: isobutylangelate, isoamylangelete, isobutylbutyrate, isobutylmethacrylate, myrcene, a-pinene, caryophylene, limonene, a-bisabolol, farnesol and others. The quality of essential oil did not depend on season so much as its chemical composition.

Chamaemelum nobile - Essential oil, a - pinene - myrcene - pinocarvone - GC/MS

The work was supported by VEGA project No. 1/0287/15

1. Balchin, M., 2004. The chemistry and biochemistry of essential oil. Aroma science, www.chamomile.co.uk/uses.htm.

2. Carnat A, Carnat AP, Fraisse D, Ricoux L, Lamaison JL. The aromaticand polyphenolic composition of Roman chamomile tea. In Fitoterapia, 2004; 75:32-38.

3. Omidbaigi R, Sefidkon F, Kazemi F. Influence of drying methods on the essential oil content and composition in Roman chamomila. In Flavour and Fragrance Journal. 2004; 19: 196-198. 


\title{
PHYTOTOXIC EFFECTS OF ESSENTIAL OILS OF SOME AROMATIC PLANTS
}

\author{
Weber J. ${ }^{1}$, Klouček P. ${ }^{*}$ \\ ${ }^{1}$ Czech University of Life Sciences Praque, Faculty of Agrobiology, Food and Natural Resources, \\ Department of Crop Production, Kamycka 129, 16521 Prague, Czech Republic \\ ${ }^{2}$ Czech University of Life Sciences Prague, Faculty of Agrobiology, Food and Natural Resources, \\ Department of Quality of Agricultural Products, Kamycka 129, 16521 Prague, Czech Republic
}

Abstract

Keywords

References
Aim Essential oils (EOs) are natural volatile complex substances produced as plant secondary metabolites (Bakkali et al., 2008). These substances have significant antibacterial, antivirotic, antimycotic and insecticidal effect (Marković a kol., 2011) and serve as self-defense to the plants. Consequently, some of the essential oils can be considered as biofungicides, bioinsecticides and so on. Moreover, some of them also demonstrated phytotoxic properties, thus could be used as bioherbicides as well. EOs influence the main physiologic plant functions as seed germination, respiration, photosynthesis, enzymatic activity and so on (Chon a Nelson, 2010).

The aim of our work is to determine the lowest phytotoxic concentrations of EOs of the selected aromatic herbs. Those EOs could be used as bioherbicides; consequently, it is important to determine their lowest effective concentration. On the other hand, in case of their use as biofungicide, it is necessary to determine their maximum acceptable dose to prevent their phytotoxic effect on the treated crop.

Material/Methods The aim of our research was to investigate phytotoxic effect of essential oils (EOs) of Cinnamomum zeylanicum, Cymbopogon citratus, Eucalyptus globulus, Melalauca alternifolia, Mentha arvensis, Origanum vulgare, Satureja montana, Syzygium aromaticum and Thymus vulgaris on separated leaves of potato (Solanum tuberosum) in following EOs concentrations $0.5 ; 1 ; 5$ and $10 \%$.

Results The most significant phytotoxic effect (5\% EO concentration) was observed for E. globulus, C. zeylanicum and S. aromaticum. On the other hand, the $0.5 \%$ concentration of all tested EOs did not have any negative effect on potato leaves.

Conclusions Plant protection products are usually applied in $0.5 \%$ EOs concentration, consequently, there should not be risk of phytotoxic effect on crop in case of the use of currently tested EOs. However, the use of EOs for herbicidal effect would require $5 \%$ EOs concentration as minimum.

allelopathy - essential oils - phytotoxicity

1. Bakkali F, Averbeck S, Averbeck D, Idaomar M., Biological effects of Essentials Oils - A review. Food and Chemical Toxicology, 2008; 46: 446-475.

2. Marković T, Chatzopoulou P, Šiljegović J, Nikolić M, Glamočlija J, Ćirić A, Soković M.. Chemical Analysis and Antimicrobial Activities of the Essential Oils of Satureja thymbra and Thymbra spicata L. and their main components. Arch. Biol. Sci., 2011; 63:457-464.

3. Chon SU, Nelson CJ. Allelopathy in Compositae plants. A review. Agron. Sustain. Dev. 2010; 30: 349-358. 